\title{
METEOROLOGY
}

ก. 6928102 NASA CR 101401

Useful

Applications of

Earth-Oriented

Satellites

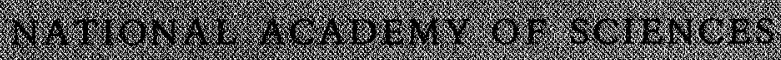

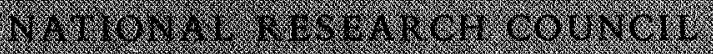




\title{
SUMMER STUDY ON SPACE APPLICATIONS
}

\author{
Chairman of Study \\ W. Deming Lewis \\ President, Lehigh University \\ Bethlehem, Pennsylvania
}

CENTRAL REVIEW COMMITTEE

Edward A. Ackerman

Carnegie Institution of Washington

Washington, D.C.

Henri G. Busignies

International Telephone and

Telegraph Corporation

New York, New York

Beardsley Graham (1968)

Columbia Plaza

Washington, D.C.

Harry H. Hess (1968)

Princeton University

Princeton, New Jersey

Edwin J. Istvan (1968)

Communications Satellite Corporation

Washington, D.C.

Thomas F. Malone

Travelers Insurance Company

Hartford, Connecticut

SENIOR ECONOMISTS AND MEMBERS

CENTRAL REVIEW COMMITTEE (1968)

Samuel Lenher (Chairman)

E. I. du Pont de Nemours \& Co., Inc.

Wilmington, Delaware

Arthur E. Burns

George Washington University

Washington, D.C.

Raymond P. Genereaux

1018 Kent Road

Wilmington, Delaware
Brian O'Brien

North Woodstock

Connecticut

Courtland D. Perkins

Princeton University

Princeton, New Jersey

Emanuel R. Piore

International Business Machines

Corporation

Armonk, New York

Allen E. Puckett

Hughes Aircraft Company

Culver City, California

J. Ralph Shay (1968)

Oregon State University

Corvallis, Oregon

H. Guyford Stever (1967)

Carnegie Institute of Technology

Pittsburgh, Pennsylvania

John R. Menke

United Nuclear Corporation

Elmsford, New York

Donald C. Slichter

The Northwestern Mutual Life

Insurance Company

Milwaukee, Wisconsin

STAFF

Eugene T. Booth, Executive Director (1967)

L. R. Daspit, Executive Director (1968) 


\section{Useful \\ Applications of Earth-Oriented Satellites}

\section{METEOROLOGY}

Prepared by Panel 4 of the

SUMMER STUDY ON SPACE APPLICATIONS

Division of Engineering

National Research Council

for the

NATIONAL AERONAUTICS AND SPACE ADMINISTRATION

Published by

NATIONAL ACADEMY OF SCIENCES

Washington, D.C. | 1969 
This is a report of work under

Contract No. NSR 09-012-909 (1967) between the National Aeronautics and Space Administration

and the National Academy of Sciences

Available from

Printing and Publishing Office

National Academy of Sciences

2101 Constitution Avenue

Washington, D.C. 20418 


\section{PREFACE}

In the fall of 1966, the National Aeronautics and Space Administration (NASA) asked the National Academy of Sciences to conduct a study on "the probable future usefulness of satellites in practical Earth-oriented applications." The study would obtain the recommendations of highly qualified scientists and engineers on the nature and scope of the research and development program needed to provide the technology required to exploit the se applications. NASA subsequently asked that the study include a consideration of economic factors.

Designated the "Summer Study on Space Applications," work began in January 1967, guided by a Central Review Committee (CRC) appointed by the Academy. The Study's Chairman was Dr. W. Deming Lewis, President of Lehigh University.

Technical panels were convened to study practical space applications and worked intensively for periods of two to three weeks during the summers of 1967 and 1968 at Little Harbor Farm in Woods Hole, Massachusetts. The work of each Panel was then reported to the Central Review Committee, which produced an overall report. Panels were convened in the following fields:

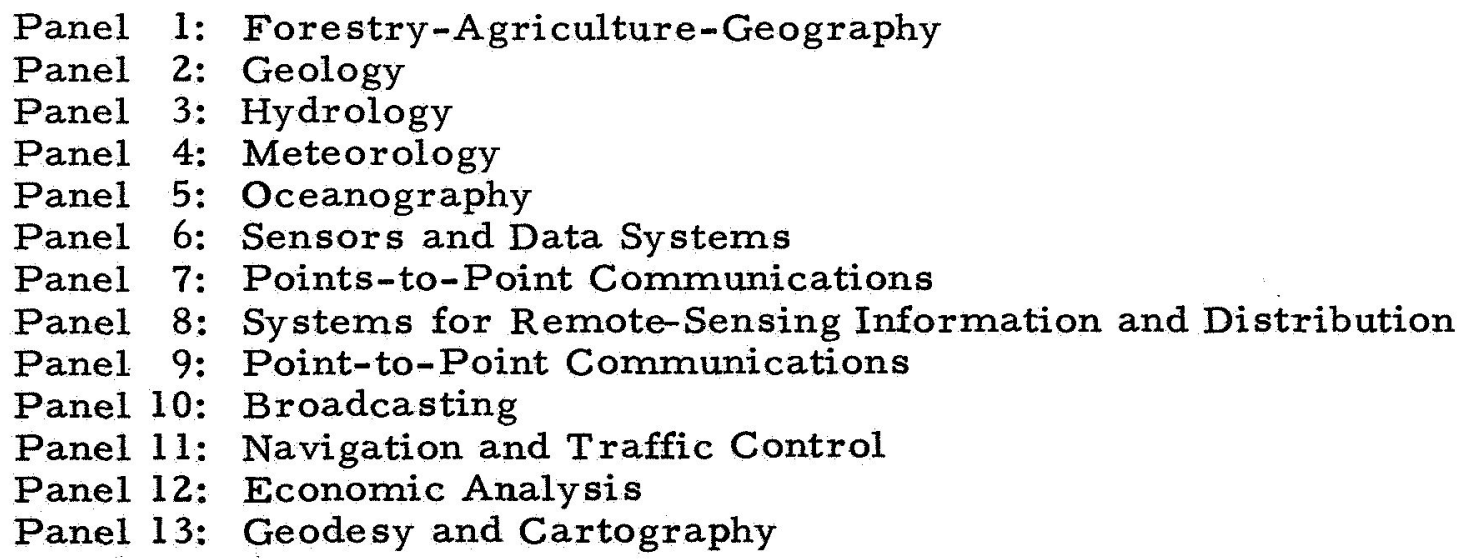

The Panel on Meteorology met and compiled an interim report during the summer of 1967. The report was reviewed and made current under the leadership of Dr. Verner E. Suomi, the Panel Chairman, during the summer of 1968 .

The major part of the Study was accomplished by the panels; the function of CRC was to review their work, to evaluate their findings, and, in the 
context of the total national picture, to derive certain conclusions and recommendations. The Committee was impressed by the quality of the panels' work and has asked that the panel reports be made available to specialized audiences. While the Committee is in general accord with the final panel reports, it does not necessarily endorse them in every detail. It chose to emphasize certain recommendations in its overall conclusions and recommendations, which have been presented in Useful Applications of EarthOriented Satellites: Report of the Central Review Committee.

In concluding this preface, it is emphasized that the conclusions and recommendations of this panel report should be considered within the context of the overall report of the Central Review Committee. 


\section{PANEL ON METEOROLOGY}

Verner E. Suomi (Chairman) University of Wisconsin Madison, Wisconsin

Charles E. Anderson University of Wisconsin

Madison, Wisconsin

Richard D. Cadle

National Center for Atmospheric Research Boulder, Colorado
Arnold H. Glaser

Allied Research Associates, Inc.

Concord, Massachusetts

Lewis D. Kaplan

California Institute of Technology

Pasadena, California 



\section{CONTENTS}

GENERAL STATEMENTS..................... 1

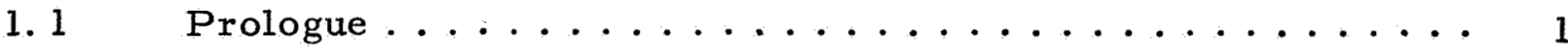

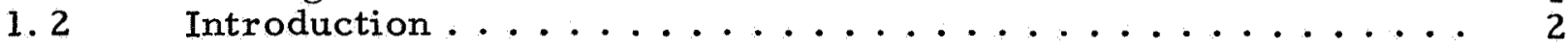

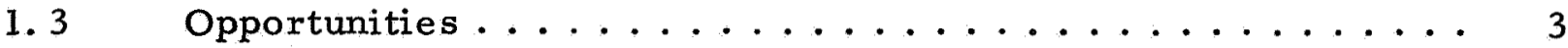

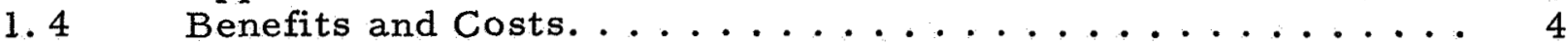

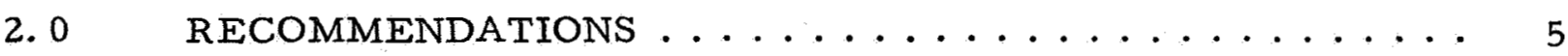

2. 1 Support of Global Atmospheric Research Program and World

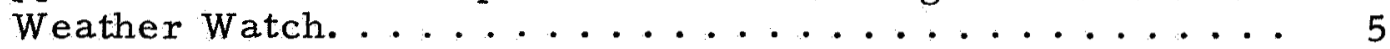

2. 2 Meteorological Geosynchronous Satellite........... 5

2. 3 Infrared and Microwave Vertical-Temperature Sounding .... 5

2. 4 Balloon-Electronics Package................ 5

2. 5 Research and Development on Promising Techniques...... 6

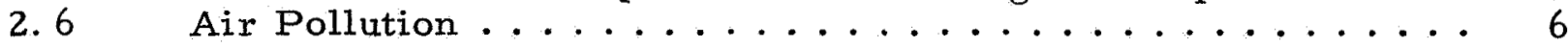

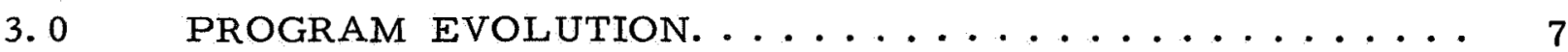

3. 1 Observational Requirements ................. 7

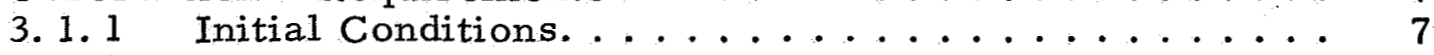

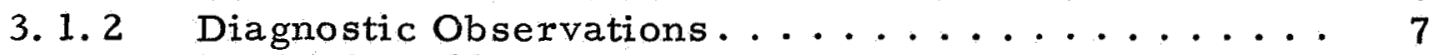

3.1.3 Real-Time Observations................ 8

3. 2 Possible Global-Observing System for the Early 1970's . . . . 8

3.2. 1 Winds, Temperature, Moisture, and Pressure

Height in the Stratosphere Using the Super-

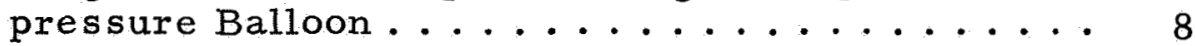

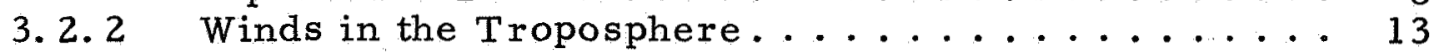

3. 2. 3 Infrared Spectrometry for Measurements of

Vertical Profiles of Temperature and Water

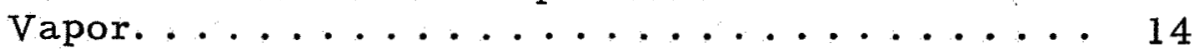

3. 2. 4 Surface-Temperature Measurement ......... 15

3.2.5 Heat-Budget Measurements.................. 15

3. 2. 6 Visible and Infrared Stripmapping plus APT. ..... 16

3. 3 Development of Communication and Data Processing,

Early-1970's System ...................... 16

3. 3. 1 Requirement for Continuing Development. ....... 16

3. 3. 2 Requirements for Numerical-Weather-

Prediction (NWP) Development........... 17

3. 3. 3 Special Data-Processing Requirements of

Imagery from Synchronous Height. . . . . . 17 


\section{CONTENTS (Continued)}

3. 3. 4 Data and Control Center for Synchronous

Page

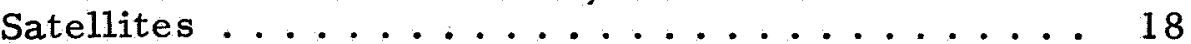

3. 3. 5 Data Processing for Global Sounding System . . . . 19

3. 3. 6 Communications for the Global Sounding System.... 19

3. 4 A Possible System for the Late 1970's ............. 20

3. 4. 1 Sounding below the Cloud-Tops ............ 20

3. 4. 2 Winds in the Tropics ................ 24

3. 4. 3 Density Determination by Radio Occultation...... 24

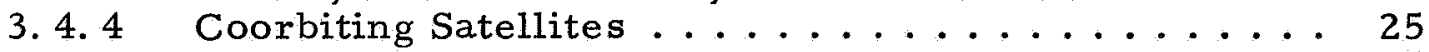

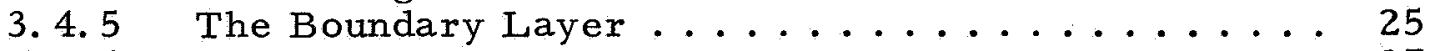

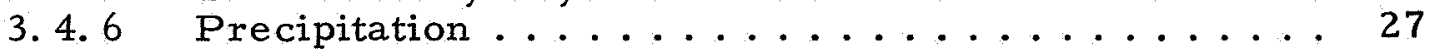

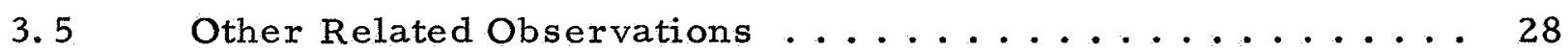

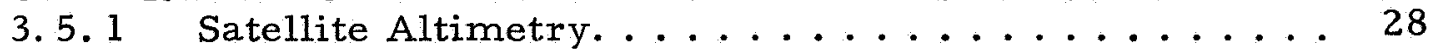

3.5.2 Temperature Difference across the Sea Surface .... 28

3.5. 3 Manned Spacecraft Support of Special Area

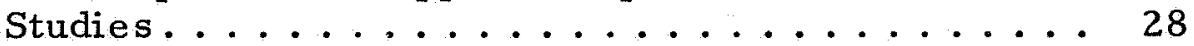

\section{APPENDIXES}

A Comments on Document NASA SP-142, "A Survey of

Space Applications" .................. 29

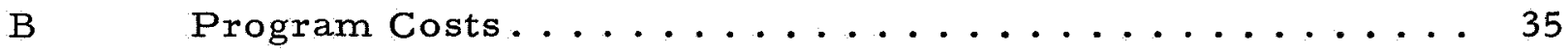

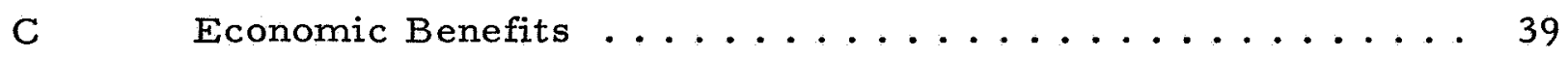

D $\quad$ A Proposed Radio-Occultation System. ........... 45

E Atmospheric-Temperature-and-Humidity-Profile

Measurement by Inversion of Microwave Radiometer

Measurements Made near the $\mathrm{O}_{2}$ and $\mathrm{H}_{2} \mathrm{O}$ Emission

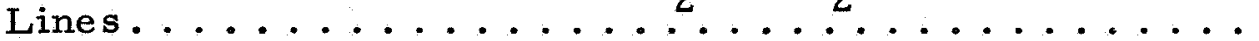

F Measurement of Ocean-Surface Temperature and

Surface-Temperature Gradient .............663

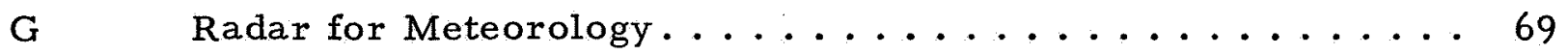

$\mathrm{H} \quad$ Application of Light Scattering and Polarization . . . . . . 75 


\section{0 GENERAL STATEMENTS}

\section{1 Prologue}

Photographic satellites now daily observe global weather patterns showing forecasters storm centers in areas inaccessible to ground observations. Geostationary satellites send high-resolution movies of the weather as it develops and can relay these movies and other weather information to the world. Yet these space applications are only the start of the new thrust that has fired the imaginations of meteorologists all over the world. Thanks to the efforts of a handful of dedicated individuals in science and technology, forecasts of the large-scale weather-the large storms that bring cold and flood and drought and the stagnant weather ripe for pollution--may soon be made up to a week or two in advance. The benefits of this information toward saving lives, preventing misery, and aiding many areas of the economy could amount to billions of dollars, The Global Atmospheric Research Program (GARP) has as its goal a system of observing the global atmosphere well enough to provide the initial conditions and updating information for the mathematical model that will yield these predictions. This program has already been mentioned by two U. S. Presidents as a possible fruit of. space activities. It has been endorsed by the World Meteorological Organization, the international body representing more than a hundred nations. Indeed, during the time the Summer Study on Space Applications was in session, members of the international scientific community were hard at work in a similar session across the Atlantic in Stockholm, hammering out requirements for global observations and calling attention to a number of scientific questions still to be resolved before the mid$1970^{\prime}$ s. In short, GARP is well under way.

Because observing the global atmosphere well enough for the numerical models cannot be considered seriously without utilizing the global capabilities of space platforms, NASA must play a key role in GARP's implementation; ESSA, as the ultimate operating agency, must work closely with NASA. While the atmospheric scientists at Stockholm considered the specification of scientific data requirements for GARP, our Summer Study group contemplated the technological requirements before us.

The synthetic atmosphere in the computer model is total. It has no gaps in area or time coverage--it completely specifies a closed physical system. Our examination of the NASA program showed that much of the real atmosphere can be specified. We also learned that, at present, it cannot be completely specified and that there are gaps to be filled or 
shored up. New techniques were presented, with exciting capabilities that suggest that the gaps can indeed be filled. NASA's research-and-development program then should be adapted to fill the se gaps.

NASA has already made an enormous and continuing contribution to this new opportunity in meteorology. The promise of being able to forecast the large-scale weather as much as two weeks in advance by the late 1970's is very real. President Johnson has said: "We will move ahead with plans to devise a worldwide weather system--using the satellite and facilities of all industrial countries. The space age has given us an unparalleled capacity to predict the course of the weather. By working together, on a global basis, we can take new strides toward coping with the historic enemies of storm and drought and flood."

\section{2 Introduction}

The use of satellite-borne instruments to observe the earth's weather is perhaps the earliest and best-known application of space technology to earthrelated problems. The past and current programs of NASA and ESSA have demonstrated to the satisfaction of all that useful weather data may be obtained by visual and infrared imaging of the cloud patterns that are ever present in the earth's atmosphere. There is no question of the qualitative utility of these data in day-to-day forecasting procedures. Nor is there any doubt that continuous high-resolution pictures from geostationary satellites will have immediate value to many users. However, for the lower-resolution but much-longer-range machine forecasting, more quantitative data are needed.

Recent advances in improving the sophistication and computational stability of numerical models of the atmospheric circulation, together with expected order-of-magnitude improvements in speed of electronic computers, should make it possible, within the next decade, to produce operationally useful forecasts of weather patterns up to a week or more in advance. The data requirements for such a program have been found to be less stringent than previously suspected (for example, the pressure field itself is probably not required, and the same might be true of the wind field poleward of 20 degrees latitude), but the three-dimensional global distribution of temperature, moisture, and clouds is required. These are the variables that can be determined most easily by sounding from satellites.

The minimum data requirement for an effective numerical weatherprediction system capable of producing operationally useful extended forecasts is the distribution, over the entire earth, of the vertical temperatureand-moisture profile, surface temperature, cloud-top temperature and height, amount of reflected solar radiation, and the wind field. For the forecasts to be reasonably accurate from the ground to the level of supersonic aircraft, the horizontal observational-grid spacing should be on the order of 500 miles, and mean temperatures should be determined both over comparable horizontal dimensions and over successive layers of about 4or $5-\mathrm{km}$ thickness from the ground to about $35 \mathrm{~km}$. Humidities should be obtained at a sufficient number of levels in the troposphere to specify the 
coarse distribution from the ground to the 200-millibar level. Each grid point should be sampled at least once a day, preferably every $12 \mathrm{hr}$. Thus modern forecasting techniques require initial values of the state variables that describe the thermodynamic and the dynamic properties of the atmosphere. In other words, the numerical weather-prediction techniques demand quantitative inputs, and, until weather satellites are able to generate the se, their use in modern meteorology will be, at best, supplementary.

\section{3 Opportunities}

The shortcoming stated above has been long recognized, and there are in existence programs and proposals to measure, with the help of satellites, the wind, temperature, moisture, and pressure over the globe, as needed by the meteorologist. The Panel, having reviewed the current research-and-development programs in satellite meteorology, feels that the opportunity now exists to focus these programs and bring into existence, by the early $1970^{\prime}$ s, a truly global meteorological observing capability.

The system is intended to complement the already-existing surface and upper-air networks around the earth. It will transmit immediate and continuous high-resolution photographs to all users. It will provide data for those ocean and land areas where the existing network has large gaps-the tropics, the Pacific and Indian Oceans in the Northern Hemisphere, and practically the entire Southern Hemisphere oceans. In performing such a function, it will help provide the input data required for GARP and it may be the forerunner of an eventual world-weather system. At the heart of the system are three recent developments:

1. The extremely successful spin-scan cameras on ATS-I, which can provide visual imaging of the earth from a stationary orbit (by positioning three or four geosynchronous satellites equipped with such devices around the equator, continuous mapping of the earth's cloud pattern--except for latitudes higher than $70^{\circ}--$ could be carried out during daylight)

2. The successful inversion of infrared-radiance profiles to yield atmospheric-temperature soundings to the earth's surface in cloudless areas or to the cloud-tops in cloudy areas

3. The successful demonstration of the feasibility of measuring temperature, moisture, height, and winds in the stratosphere by long-lived, superpressure-balloon* platforms

*These superpressure balloons are referred to by various terms. A superpressure balloon actually floats on a constant-density surface, at the altitude where the weight of the displaced air is equal to the gross load. The constant-density surface is almost horizontal; therefore, constant-density balloons are sometimes called constant-level balloons. They are also sometimes referred to as horizontal-sounding balloons. 
The Panel feels that these developments are encouraging enough to warrant a determined effort by NASA to seek to assemble the se several techniques, together with the existing TIROS-operational-satellite (TOS) capability, to yield the first version of a global-observing system.

Although the panel urges the early implementation of a system based on current research and development, the Panel recognizes that this first version will suffer several shortcomings. To overcome these, and to bring improved techniques into the program, the Panel foresees the need for continuing research and development, with the clear objective of producing a greatly improved system by the late $1970^{\prime}$ s or early $1980^{\prime}$ s.

\section{4 Benefits and Costs}

Information from the recommended system will have two forms: high-resolution real-time photographs (time lapse movies), and lowresolution 1 - to 2 -week forecasts. The former will aid the many areas of commerce and industry that must react quickly to local weather change. These benefits may be smaller than those of long-range forecasts, but they can be realized much sooner.

The benefits of 5- to 7-day weather forecasts for the United States with an accuracy comparable to the currently available 24- to 48-hr forecasts are estimated to exceed by many times the cost of the system (see Appendixes $B$ and C). It is clear that benefits will accrue to many segments of our national life such as agriculture, construction, transportation, recreation, commerce, and defense. 


\section{0 RECOMMENDATIONS}

In reviewing the proposed NASA program of space applications to meteorology, the Panel feels that NASA has a unique opportunity to make a significant contribution to the United States and to the world.

In its assessment of the national economic benefits that would accrue from the enhanced long-range weather-forecast capability promised by the new global-observing capability, the Panel is satisfied that substantial benefits possibly can be realized in the U.S. economy alone.

\subsection{Support of Global Atmospheric Research Program and World Weather Watch}

The Panel recommends that NASA continue to direct its meteorological-satellite program to meeting the observational requirements of GARP and the World Weather Watch programs and respond as needs develop for new technology and support for the GARP field programs.

\subsection{Meteorological Geosynchronous Satellite}

The meteorological geosynchronous satellite is a more effective platform than it was first considered. The Panel recommends that NASA proceed to develop a fully integrated meteorological geosynchronous satellite to be available by 1971 . Both visible and infrared images should be available in real time, as well as a data-collection and relay capability. Display equipment to present time-lapse views of these data should be developed.

\section{3 Infrared and Microwave Vertical-Temperature Sounding}

NASA's infrared and microwave vertical-temperature-sounding programs should be reoriented to include both polar and geosynchronous satellites, and be developed into integrated systems capable of satisfying known data requirements for long-range numerical weather forecasting.

\section{4 Balloon-Electronics Package}

A high priority should be assigned to development of a suitable balloonelectronics package that fully meets the weight requirements to prevent its being a hazard to aviation. A simple, lightweight, low-cost, yet meteorologically useful balloon package must be developed, and it should not be compromised in the interest of spacecraft commonality. 


\section{5 Research and Development on Promising Techniques}

Research and development should be started immediately on techniques that show promise for obtaining soundings of the atmosphere below clouds, such as microwave radiometry and the radio-occultation technique.

\section{6 Air Pollution}

In addition to NASA's development of specific meteorological-sensing capabilities, the Panel is concerned about the rising amount of worldwide air pollution. The Panel feels that a real service to the world community could be rendered if background amounts of pollutants could be monitored from space. The Panel recommends that NASA encourage and support a ground-based research-and-development program in high-resolution spectroscopy of polluted air, to evaluate the possibility and merit of detecting and monitoring atmospheric pollutants from satellites. 


\section{0 PROGRAM EVOLUTION}

\section{1 Observational Requirements}

Those who fashion mathematical models of the atmosphere constantly reiterate (and so will we) the importance of treating the atmosphere as a complete physical system. There are many examples of these models, some simple and some complex. As the models become more sophisticated representations of the real atmosphere, they will need more sophisticated observations.

\section{1. 1 Initial Conditions}

Observations of initial conditions include mainly the threedimensional distribution of the mass of the atmosphere expressed as density or temperature and pressure. Also included is the distribution of the thermodynamically and optically active gases such as water vapor and, to a lesser degree, ozone.

Winds are also needed as initial conditions. The need for wind information is a function of latitude. In the middle and high latitudes the winds can be deduced surprisingly well from the temperature or mass field alone, because the spin of the earth forces the winds to blow parallel to the isobars. In the tropics, information on pressure and temperature, as we are able to measure them, cannot be used. In the tropics we must have the winds themselves. What is more, we must have them to high accuracy so that the divergence or convergence can be determined.

\subsubsection{Diagnostic Observations}

Observations of how much heat is transferred from the ocean to the atmosphere and how much heat is gained from the sun and lost to space by radiation are very important control observations. They are not used as input to the model. The model, if it is to be realistic, must predict these heat exchanges with the external environment. Global rainfall is also such a parameter. Its geographical distribution, particularly over the oceans, where it is now virtually unknown, and its total amount represent an important upper bound for the evaporation. A test of the model's performance is to see how well it predicts the amount of evaporation required for heat balance. This prediction may be verified over a long time period by rain-gauge observations. 


\section{1. 3 Real-Time Observations}

Continuous high-resolution cloud pictures will contribute to numerical weather prediction indirectly, since cloud motions can yield winds. However they will contribute directly to increased efficiency and savings in many areas of the economy. They are included here as an "observational requirement" to ensure that this area of user needs is not overlooked while pursuing the goal of long-range forecasting.

\section{2 Possible Global-Observing System for the Early 1970's}

In this section we have drawn together satellite measuring systems whose feasibility has been demonstrated. This is not to say they have been flight-tested. Moreover, we have slightly modified existing systems into a package that we feel best fits the measuring system to the needed observations.

In Figure 4.3. 1 we indicate schematically the principal meteorological observations that are required for a minimum system. In Table 4. 3. 1 we indicate how we expect to obtain these observations and include certain support observations that will assure the quality of the primary ones. Finally, in Figure 4.3.2 we show a schematic of the entire system. There are many ways to arrange these observations and measuring techniques, but we feel that this particular arrangement allows us to emphasize that the needed observation--and not the measuring device in the satellite--is most important. Continued support of this R\&D effort to bring these components of the system into a state of readiness deserves the very highest priority in the expenditure of the limited resources available.

We begin from the top of the atmosphere and work down.

\subsection{Winds, Temperature, Moisture, and Pressure Height in the Stratosphere Using the Superpressure Balloon}

The superpressure balloon provides an in situ measurement, and its information is collected by the satellite. The balloon's horizontal dis placement can yield wind, and sensors can be included to measure temperature, $T$; water vapor, $\rho_{\mathrm{w}}$; pressure, $\mathrm{P}$; and radio altitude (above the ocean), Z. By including radio altitude, the information from the floating balloon can be used as a reference level. The constant-level-balloon system could give excellent measurement of the structure of the stratosphere.

The stratosphere moisture cannot be obtained by infrared sounding systems described later. Nevertheless, the small amounts of moisture in the stratosphere play an exceedingly important role in the stratosphere's radiation balance. Therefore, a moisture-determination capability is included in the balloon system. It is hoped that the moisture distribution obtained during the period of utilization of balloons will make it unnecessary to observe this parameter on a continuing routine basis. The key element for the se in situ measurements is the superpressure balloon. 


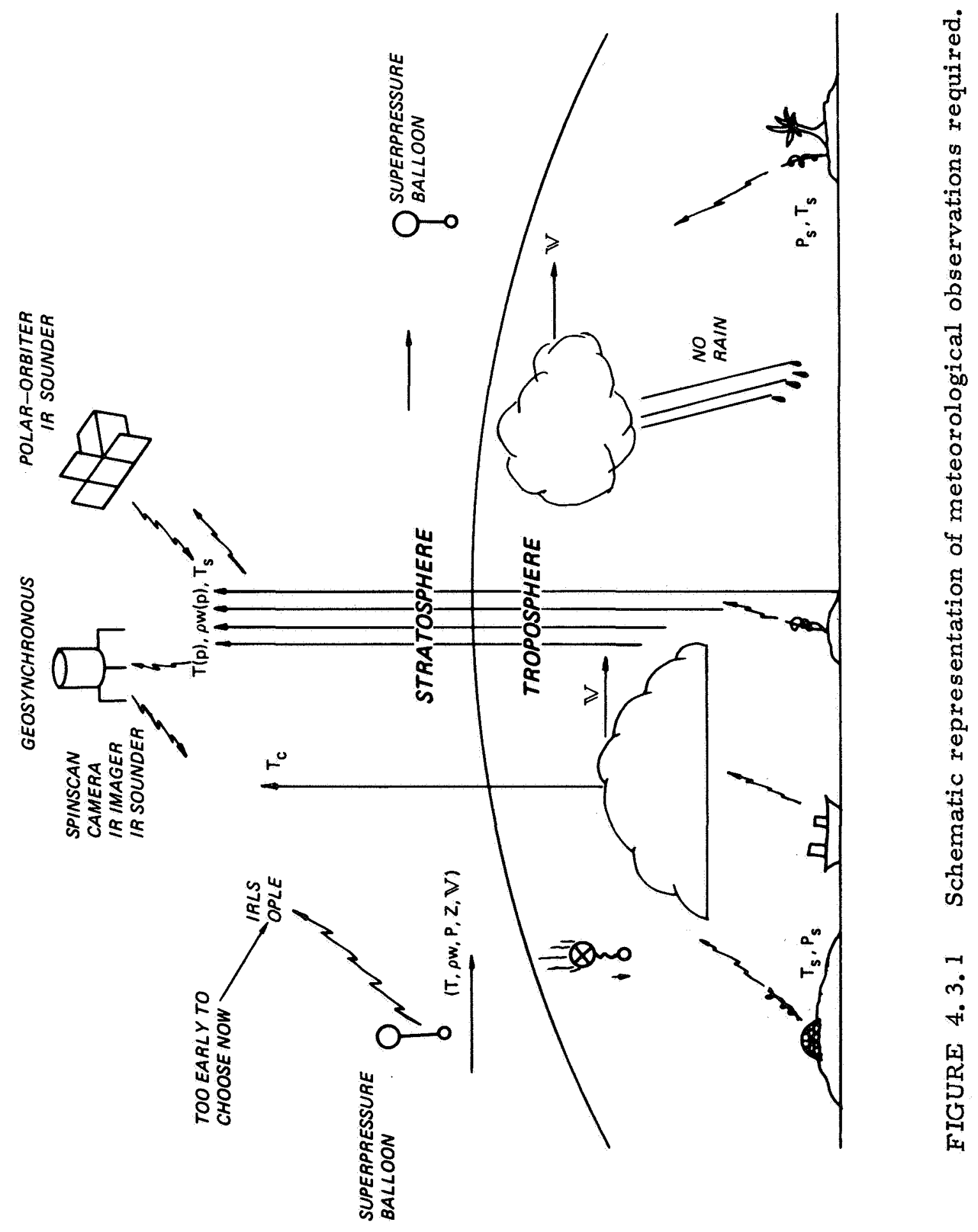




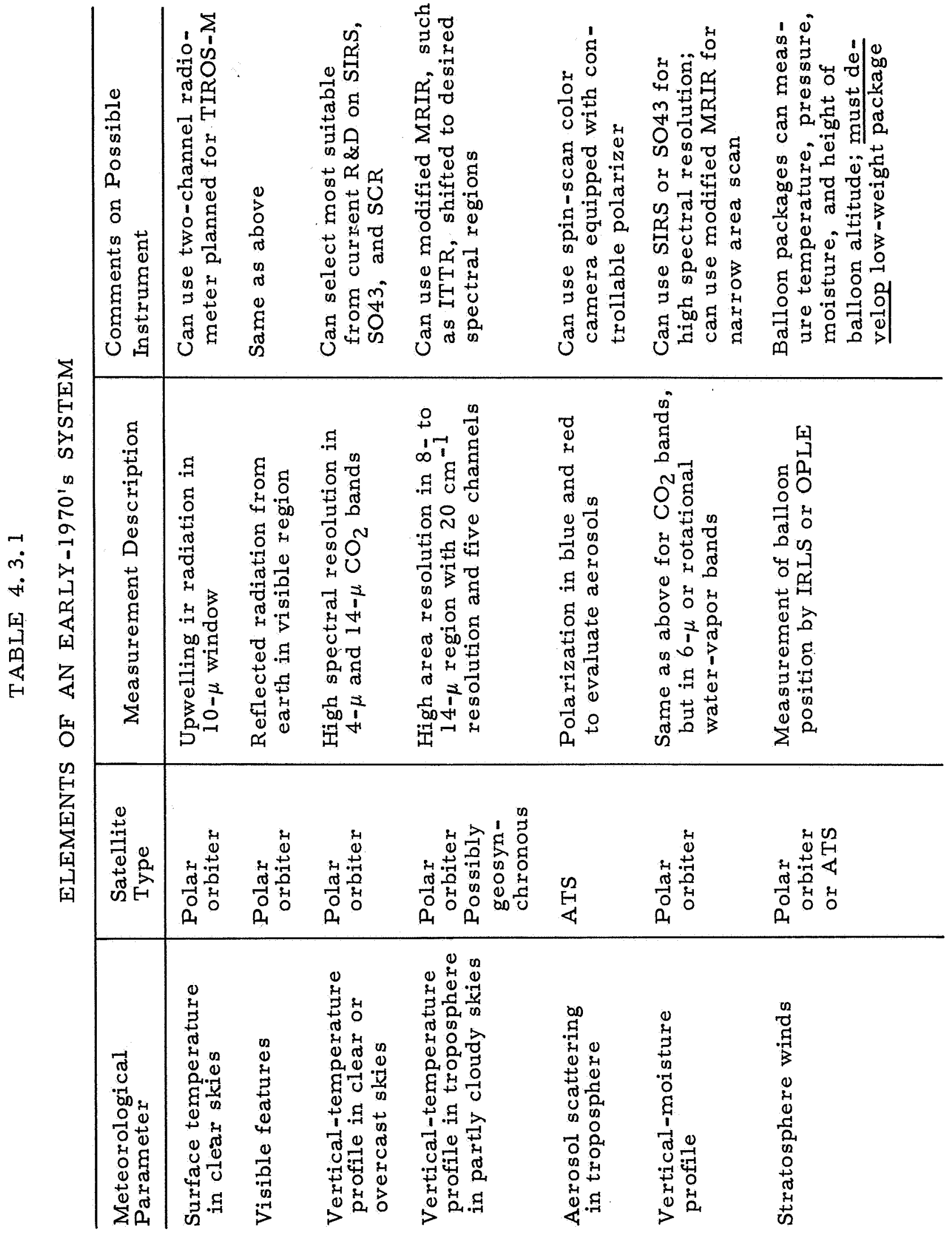




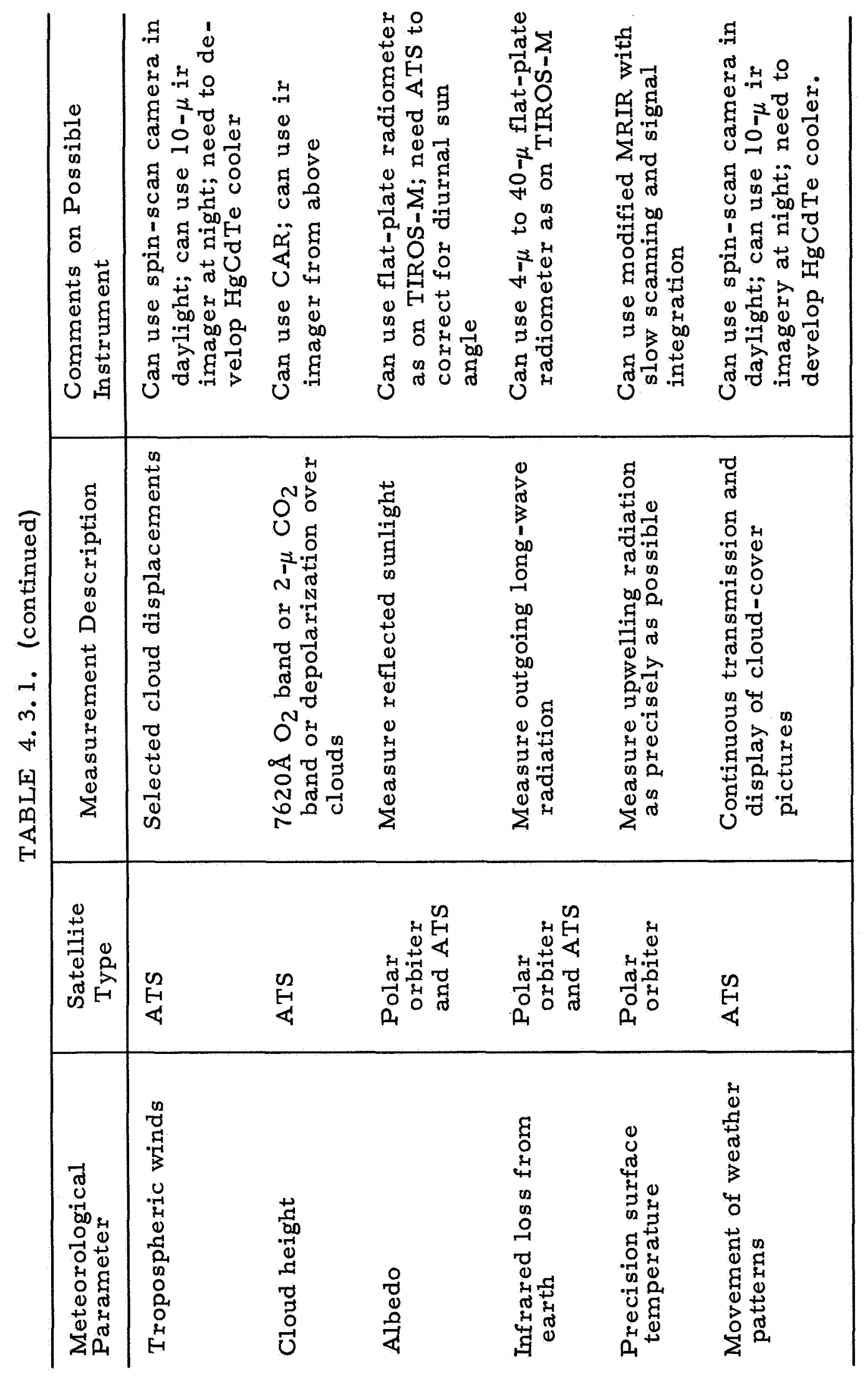




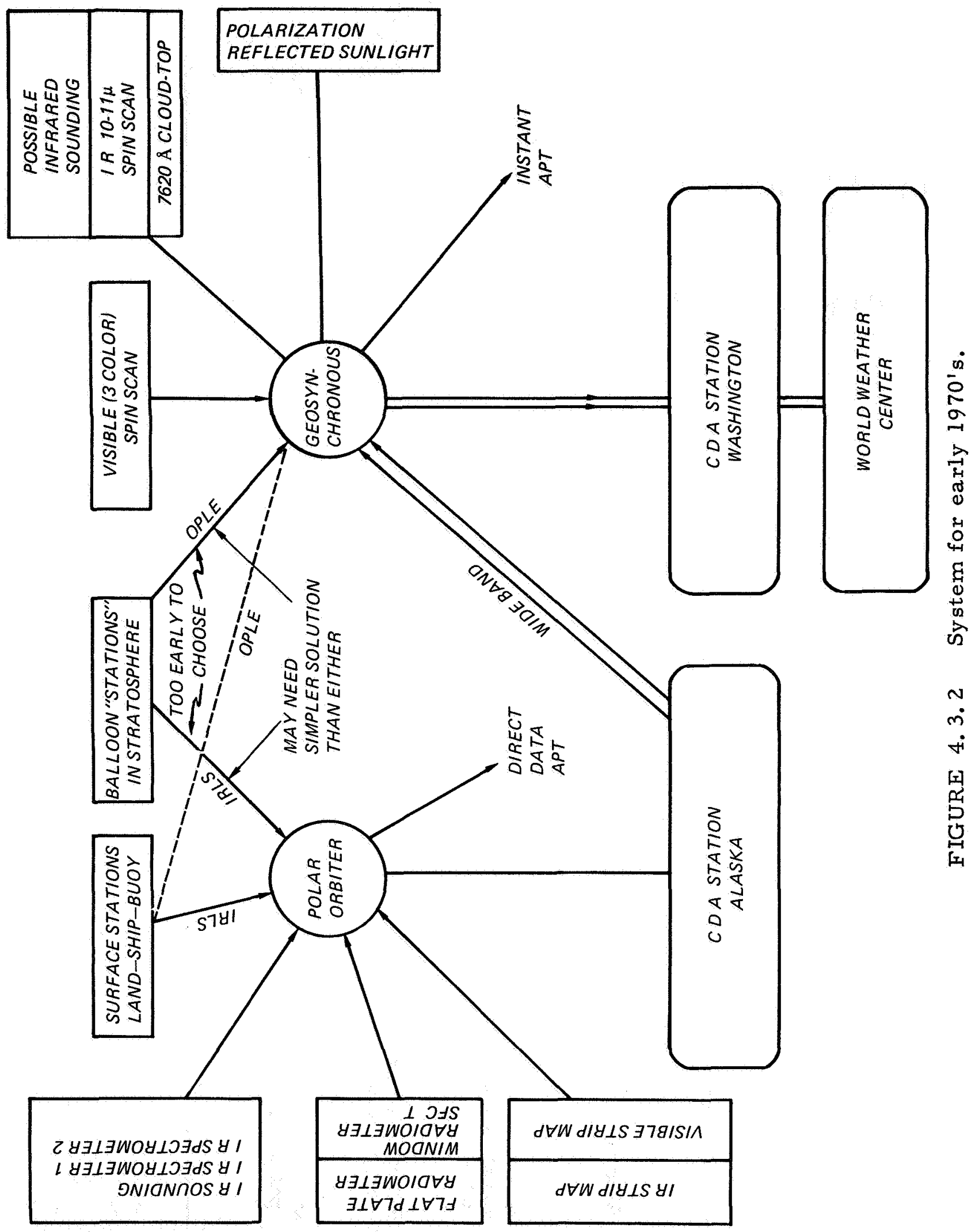


Experiments conducted by Lally during 1966-1967 show that long flights of superpressure balloons in the stratosphere are feasible. Some of his test balloons have circumnavigated the globe many times, and some are still flying after more than 200 days. However, the superpressure balloon is in trouble in the troposphere. Apparently, icing conditions within clouds cause the difficulty. The French are having a similar experience in the EOLE program. At the moment we cannot count on using the balloons in the troposphere. Therefore, we will use balloons only for measurements in the stratosphere.

The balloon is only one part of the horizontal sounding system. An electronic package, which allows one to locate the balloon and telemeter its measurements, is also needed. NASA has two systems to do this. One, the interrogation, recording, and location system (IRLS), uses the Nimbus spacecraft as the data collector and relay and locator; the other system, the Omega position location experiment (OPLE), uses a geosynchronous satellite such as ATS-C. The engineering feasibility of each system has already been demonstrated, but the operational capability has not. In order to be useful, the balloon system and the electronic system must be mated. This is basically a problem in packaging. If it is not to be a hazard to aviation, the entire electronics package and its associated power supply must not weigh more than 200 to $400 \mathrm{~g}$. Fortunately, recent advances in integrated-circuit technology help bring this goal within reach. The Panel wishes to emphasize in strongest terms that the entire investment in IRLS and OPLE will have been in vain, as far as meeting the superpressure-balloon requirements are concerned, unless these extremely stringent packaging problems are overcome. Moreover, the packages must have a reasonable cost. Even when restricted to flights in the stratosphere, 500 to 2000 balloons are involved in the system. Simple arithmetic shows that the system can also be priced out of use.

\subsubsection{Winds in the Troposphere}

As noted above, we cannot use balloons to measure winds in the troposphere. This is not so critical in the middle and high latitudes because it is possible to calculate the motion at these latitudes from the temperature fields. In the tropics, as we have already mentioned, we are forced to use the motions of selected clouds.

In the tropics, the horizontal wind shear and vertical wind shear are small compared with typical values at higher latitudes. Thus the clouds will not be "torn apart" during the observation, and we do not need as many vertical data levels. The spin-scan camera pictures from the geosynchronous satellite ATS-I show that one can indeed obtain good wind measurements by measuring the displacement of selected clouds.

The value of these observations would be enhanced greatly if we also had cloud-top-height information. While some height information can be inferred from the shapes, brightness, and motions of these clouds, we really need to be able to measure cloud height. One way to determine cloud height is to measure the cloud-top temperature. This has already been demonstrated using infrared radiometry from low-orbiting satellites such as TIROS and Nimbus. Studies show that infrared can be used at synchronous altitude as well. In order to do this, a development program is needed to make quantum detectors such as $\mathrm{HgCdTe}$ small and sensitive enough. In addition, a program to develop a superb radiation cooler must proceed with the development of the detector. In order to reject every milliwatt of 
unwanted energy, the radiation cooler must have a large solid-angle view of space. This requirement will undoubtedly affect the spacecraft structure, but it must not be compromised. The radiation cooler must reach temperatures as low as $70^{\circ}$ to $90^{\circ} \mathrm{K}$, or all performance will be lost completely. The ability to obtain cloud heights as well as their motion would, of course, make it possible to get winds from cloud motion at higher latitudes also. The minimum system needed in the early-to-middle 1970's should include four synchronous satellites with both visible and infrared capability.

The infrared imaging capability at synchronous altitude would allow continuous day and night time-lapse photo coverage of severe storms and convective systems. The added continuity would be a highly useful asset of the system.

We have included simple polarization measurements as well. They provide support measurements for the infrared sounding system described later.

\section{2. 3. Infrared Spectrometry for Measurements of Vertical Profiles of Temperature and Water Vapor}

A key milestone in our ability to provide the global mass distribution for the mathematical model was crossed about two years ago. This was the successful test of the concept of using spectral measurements of the upwelling infrared radiation in the $14-\mu \mathrm{CO}_{2}$ band. Temperature profiles accurate to $\pm 1^{\circ} \mathrm{C}$ were obtained on flights from balloons. This technique becomes the "workhorse" of our early-1970's global observing system. Several types of the se spectrometers have been included in the Nimbus B and D programs. The Nimbus D complement of experiments is admirably suitable for obtaining these minimum data. The improved satellite infrared spectrometer (SIRS-B) will provide the temperature and humidity data, with sufficient vertical and horizontal resolution, in the clear areas and above the clouds. It will also provide surface temperatures in the clear areas and cloud-top temperatures elsewhere. Data from the selective chopper radiometer (SCR), will allow an increase in the vertical resolution of the derived temperature profile and provide temperature at levels in the atmosphere used by subsonic aircraft. The cloud-top altimeter-radiometer (CAR) will determine the pressure at the cloudtops, and, together with the image-dissector camera system (IDCS) and the high-resolution infrared radiometer (HRIR), it will provide cloud information necessary for the interpretation of the SIRS and SCR measurements and for direct use in numerical weather prediction (NWP). It may also make a crude estimate of low-latitude winds.

The major gap in the global data using the infrared sounding system is the lack of data below clouds. Since cloudy skies are highly correlated with low pressure and warm temperature, there is a danger that these samples will be biased toward cold-air masses. This must be looked into more carefully if we are to take full advantage of these measurements. The physics of infrared spectrometry places limits on the trade-off between spectral resolution and geographical resolution. One can choose high spectral resolution in order to sound the atmosphere both more accurately and to higher altitude. 
To do this, one must collect more energy, either by increasing the size of the optic and keeping the same field of view, or by keeping the same optic and increasing the field of view. The latter choice is more susceptible to the partly cloudy situation. If one wishes high geographical resolution in order to see between the clouds more often, one must use wider spectral intervals to gain the energy. The advantage of good geographical resolution is that it increases one's chances of seeing between the clouds and of looking farther down into the atmosphere.

The Panel recommends that both systems be used, since they complement each other very well. The high-geographical-resolution, coarsespectral-bandwidth instrument can handle the situation that seems partly cloudy to the high-spectral-resolution instrument well enough to allow a useful first approximation of the partly cloudy situation. The wide-band, high-geographical-resolution instrument can be made available by modifying the filters of the medium-resolution infrared radiometer (MRIR) to meet the se new requirements.

We therefore recommend that two complementary ir spectrometers be included in the proposed system and that the necessary research and development to accomplish this be done.

Infrared sounding of the atmosphere is sensitive to the presence of aerosols. In order to determine whether aerosols are present and to estimate their amount, a polarizer has been included on the ATS spin-scan color camera. The camera should be capable of rotating its polarizer through a few selected angles on command from the ground. This is a very simple addition to the spin-scan camera. Appendix $H$ indicates that it is possible to obtain a surprising amount of quantitative information on the atmosphere from complete and accurate polarization measurements. Most, but not all, of these benefits will become available by the addition of a simpler polarizer to the ATS color camera.

\subsection{Surface-Temperature Measurement}

Surface temperature can be estimated fairly well over the oceans because of the great heat capacity of the ocean. We must measure surface temperature over land and over snow especially, because the low heat conductivities of these surfaces allow the surface temperature to undergo large excursions. Also, in order to monitor air-sea interactions, one wants surface temperature accurate to $1 / 4^{\circ} \mathrm{C}$ over the oceans. Surface temperature, but not to this accuracy, will be obtained from the ir portion of the strip imager we mention next and also from the window bands of the spectrometers mentioned earlier. We recommend, however, that a separate radiometer in the cleanest portion of the $10-$ to $11-\mu$ band be included to provide the greatest possible accuracy--possibly by employing a larger integration time and high-accuracy automatic calibration.

\subsection{Heat-Budget Measurements}

Albedo and terrestrial-radiation loss to space are important control measurements. In order to be useful, the radiometers must measure 
sunlight uniformly over the entire solar spectrum and the terrestrial radiometer must have uniform sensitivity over the entire long-wave spectrum. Provision for accurate in-flight calibration is a necessity. The net radiation that drives the atmospheric system is the difference between two large numbers, i. e., the incoming solar and the outgoing reflected solar and terrestrial radiation. Precision of measurement and stability of sensitivity are the prime requirements rather than high geographic resolution. Therefore, flat-plate radiometers are included in the system. These may be available from the TOS program.

It is not possible to solve for the reflected solar radiation using a polar-orbiting satellite, because one has the opportunity to sample the solar radiation only at one time of the day. In order to account for the diurnal change in cloudiness, one must derive an appropriate weighting function from the continuous geosynchronous ATS observations. The ATS observation in the ir will also allow one to derive a weighting function for the derived changes in long-wave radiation. Thus the ATS observations yield very important support observations to the heat-budget measuring system.

\subsubsection{Visible and Infrared Stripmapping plus APT}

One might wonder why an intermittent visible and ir high-resolution stripmapping plus automatic-picture-transmission (APT) capability should be included when a continuous system for these same parameters is available from ATS. We include it as a support observation for all the other measurement systems aboard the polar orbiter, because it provides images in the same geometry as the observation of the primary system. Further, it covers both poles in every orbit, thereby providing frequent, complete global coverage. The desirability of the APT feature is self-evident.

The Panel feels that these sets of observations constitute a realistic goal to be achieved in the early $1970^{\prime} \mathrm{s}$. Some elements of the system will come into being earlier. The Nimbus test vehicles may become the first polar orbiters. The TIROS-M should be designed toward these capabilities also. This set of global observations will make possible the first real opportunity to observe and predict the global atmosphere as a closed physical system.

\section{3 Development of Communication and Data Processing, Early-1970's System}

\section{3. 1 Requirement for Continuing Development}

To date, the observations from the sensors flown on TIROS, Nimbus, and ATS have been promptly applied to both research and operations. Exceptions have occurred where extensive computational processing is required before the observations can be applied or where data communications have been too slow to permit experimental operations. Prompt availability of data, both for research and for operational experiments, is essential to assure timely feedback of information into ongoing programs of spacecraft, data-processing, and forecast development. 


\section{3.2 Requirements for Numerical-Weather-Prediction (NWP) Development}

NASA is urged, in the development of the Nimbus, ATS, Apollo applications, and in future experimental missions to assure adequate timely data communications to experimental data users at ESSA and elsewhere. ESSA, in turn, should take certain steps to assist NASA in maintaining the rapid pace of improvement of global observation. Sensor systems intended to supplement the observation network for numerical weather prediction are now deemed feasible, and it should soon be possible to take from space nearly all observations required for NWP.

However, the NWP system now in operational use by ESSA, as well as the various experimental NWP programs, cannot readily accept nonsynoptic data, that is, data taken at times significantly different from the time taken as the initiation of the forecast process. Consideration is being given by ESSA to altering the organization of the prediction scheme to permit acceptance of observations taken at any time. This would be done by maintaining in the computer a dynamic analysis, which is itself a shortterm forecast from the time of the last data entry, modified to conform to the currently available data. The operational predictions would start from the most recent dynamic analysis.

Removal of the synoptic-data requirement will make the orbitingsatellite products compatible with NWP practice without the necessity for generating synthetic synoptic data by temporal interpolation or extrapolation, or, worse, by ignoring either the data themselves or the fact that they are not synoptic.

A dynamic-analysis scheme of even greater sophistication would be required to take full advantage of trajectory data from constant-level balloons collected by systems such as IRLS, OPLE, or EOLE. The greatest analytic benefit will be gained by adjusting the dynamic analysis so that trajectories computed from successive analyses conform to observed positions of the balloons.

ESSA should be made aware of the necessity to initiate studies and development leading toward a dynamic-analysis base for experimental and operational NWP so that the NWP system will be ready to accept the global but nonsynoptic data made available by satellite sounding systems. Experimental data of this type will be available with the flights of Nimbus $B$ and Nimbus D; availability of a suitable medium for directly evaluating the output of the new sensors will lead to more rapid and economical development of an operational global satellite observation system.

\section{3.3 Special Data-Processing Requirements of Imagery from Synchronous Height}

The sensor outputs from a geosynchronous satellite can and should be of substantially greater volume than those from lower-orbiting satellites. On the other hand, the speed at which the geosynchronous data must get to the user is at least 10 times greater than that normally required for data. 
from low orbit. This new requirement for handling perhaps 10 times as much data at 10 times the speed must receive the attention it deserves.

As an example, near-real-time digital processing of cloud data from geosynchronous satellites, such as ATS-I, to obtain wind velocities through cloud movement, seems to require computer speed and capacity at the far edge of the current state of the art. Data volume and resolution from future geosynchronous satellites will increase, making development of an efficient technique nearly mandatory. This is particularly important since cloud motion shows the greatest immediate promise of providing essential observations of wind velocity in the tropical troposphere.

\section{3. 4 Data and Control Center for Synchronous Satellites}

The geosynchronous satellite will apparently become an important component of the global meteorological-satellite system. The principal advantage of the geosynchronous satellite is near-constant surveillance of the weather of a large part of the globe and the ability to concentrate observation, at high resolution in space and time, on areas of rapidly developing mesoscale weather. Proper utilization of this capability calls for creation of a man-controlled data system materially different in organization from that used for low-orbiting satellites. In particular, the satellite-command, data-readout, preliminary-data-interpretation, and data-communication functions must be concentrated into a single experimental synchronous meteorological satellite center (SMSC).

The center will require special equipment, some of which can be envisaged at this time. A device will be required to convert recent images taken in both the visible and ir regions and by radar into time-lapse format, to be played forward and backward to establish current weather trends. This tool may revolutionize short-range forecast practice.

Equipment will be required to extract wind information from cloudand rain-area motion and simultaneously to call out important cloud development; this equipment must be expandable to encompass the vertical dimension that will be introduced by measurement of cloud-top height from infrared temperature or from oxygen-absorption altimetry.

Facilities will be required to obtain extra-high-resolution images of parts of the earth, either by satellite command or by ground processing. These will form the basis for prediction of, for example, severe weather.

Finally, facilities are needed for speedy transmission of mesometeorological data to local weather-data users. Expansion of the concept of the current ATS-I weather-facsimile (WEFAX) experiment, in which sections of spin-scan camera pictures are relayed at APT frequencies through the communication repeater of the same satellite, will offer a means of supplementing local networks of the World Weather Watch (WWW) to permit rapid dissemination of, for example, severe weather warnings and local summaries. In some areas, the WEFAX link may become the basic local network. 


\section{3. 5 Data Processing for Global Sounding System}

The proposed set of observations for the early 1970's will entail a heavy data-processing load. The scope of most of this data processing is fairly obvious from the description of the observations. No attempt will be made here to evaluate the volume of data processing quantitatively, since this is dependent upon such factors as the methods used and the sampling rates adopted. Inspection will show that processing requirements will far exceed ESSA's current meteorological data-processing volume.

An unusual requirement will be the joint synergistic processing of the outputs of several sensors to provide corrected observations. This entails the establishment, even at the experimental level, of an integrated data-processing system capable of working in near-real time.

Some of the types of processing that will be required are:

Inversion. This will be required for such experiments as the satellite infrared radiometer system (SIRS), S034 and extensions, S050, and the selective chopper radiometer (SCR). Techniques now available appear to guarantee stable inversion and occupy but a few seconds of IBM-7094 time per inversion. The number of inversions to be performed, however, is so great that we must contemplate the nearly full-time use of a 7094-class computer to keep up with the flow.

Accurate Geographic Referencing. Geographic-referencing-accuracy requirements will be in proportion to the resolution of the sensor. Normally, the requirements will not be stringent. Exceptions occur where data from dissimilar sensors are to be used jointly, or where differences are to be taken between a pair of observations, as in the case of wind determination from cloud motion.

Joint Processing. In a number of cases, the output of one data reduction should be used to control or correct the processing of the output of another sensor. Similarly, cloud-cover observations, using either synchronous or near-earth satellities, can be used as a control on infrared soundings. Where the opening in the clouds is less than the field of view of the sounder, different inversion procedures must be used. The jointprocessing capability allows one set of observations to serve as a quality control on certain others.

A number of other cross-checks between observations are also in order to validate the output of the observation system. Typical cross-checks are temperatures derived from different sounding systems and the temperature of a cloud-top compared with that of adjacent free atmosphere. In addition, routine comparison with available radiosonde and surface data is required to give an overall validation.

\section{3. 6 Communications for the Global Sounding System}

Since the bulk of the data from the polar-orbiting satellite will be received at a command and data-acquisition station in Alaska, conventional 
landline transmission of the sharply increasing volume of data back to Washington may become economically unattractive. A synchronous satellite, if located anywhere in the wide region where it can see both Fairbanks and Washington, can serve as an economical data relay as well as provide a return path for satellite-command codes. Since our proposed system for the early 1970's includes both polar-orbiting and synchronous satellites, the inclusion of such a link in the synchronous system will be desirable.

\subsection{A Possible System for the Late 1970's}

There are major gaps in the satellite sounding system suggested for the early 1970's that require immediate attention if fully effective operational weather forecasts are to be made by the end of the decade. The sounding system as presently conceived will not provide the temperature, moisture, or wind below the cloud-tops, nor will it provide sufficient vertical resolution in the lowest kilometer of the atmosphere, even in the cloudless areas. It will not provide sufficiently detailed wind profiles in the tropics. The soundings will not have sufficient horizontal or vertical resolution to keep up with the developing capabilities of electronic computers and NWP routines. Critical data needed for controls on the forecasts, such as precipitation distribution and transfer of energy and moisture at the boundaries, will not be measured. It is the opinion of this Panel that a satellite sounding system that eliminates the se deficiencies can be developed in an 8- to 10year period, but that this will require a reorientation of system concepts and immediate work on major new research and development. The fact that we can think of the development of an integrated system on such a short time scale is due in part to an enlightened NASA policy of encouraging the development of atmospheric sounding techniques to their present advanced state.

Figure 4. 3. 3 illustrates the key elements envisioned in the improved system. Table 4.3.2 lists the meteorological parameters desired, together with suggestions as to how they may be obtained.

\section{4. 1 Sounding below the Cloud-Tops}

Clouds are opaque to infrared radiation, except for very thin cirrus clouds, which are partially transparent. Preliminary studies of the spinscan camera pictures taken from ATS-I show that much of the earth is covered by clouds and that the probability that a random 200-mile x 200-mile area is cloudless is on the order of 10 percent. Thus vast volumes of the most meteorologically important parts of the atmosphere will not be sounded by the early 1970's. Although the difficulty would be partially overcome by using the HRIR and visible imagery to interpret the infrared data in the areas of broken clouds, and the cloud heights and temperatures to guess at the temperature profile below the tops of overcast clouds, the data will be greatly degraded relative to the accuracy that can be obtained in the clear areas. The situation would not have been greatly improved by the incorporation of conventional microwave radiometry, since the problem of elimination of the effects of cloud and precipitation on the outgoing radiation is quite formidable, enough to determinate the sounding accuracy. 


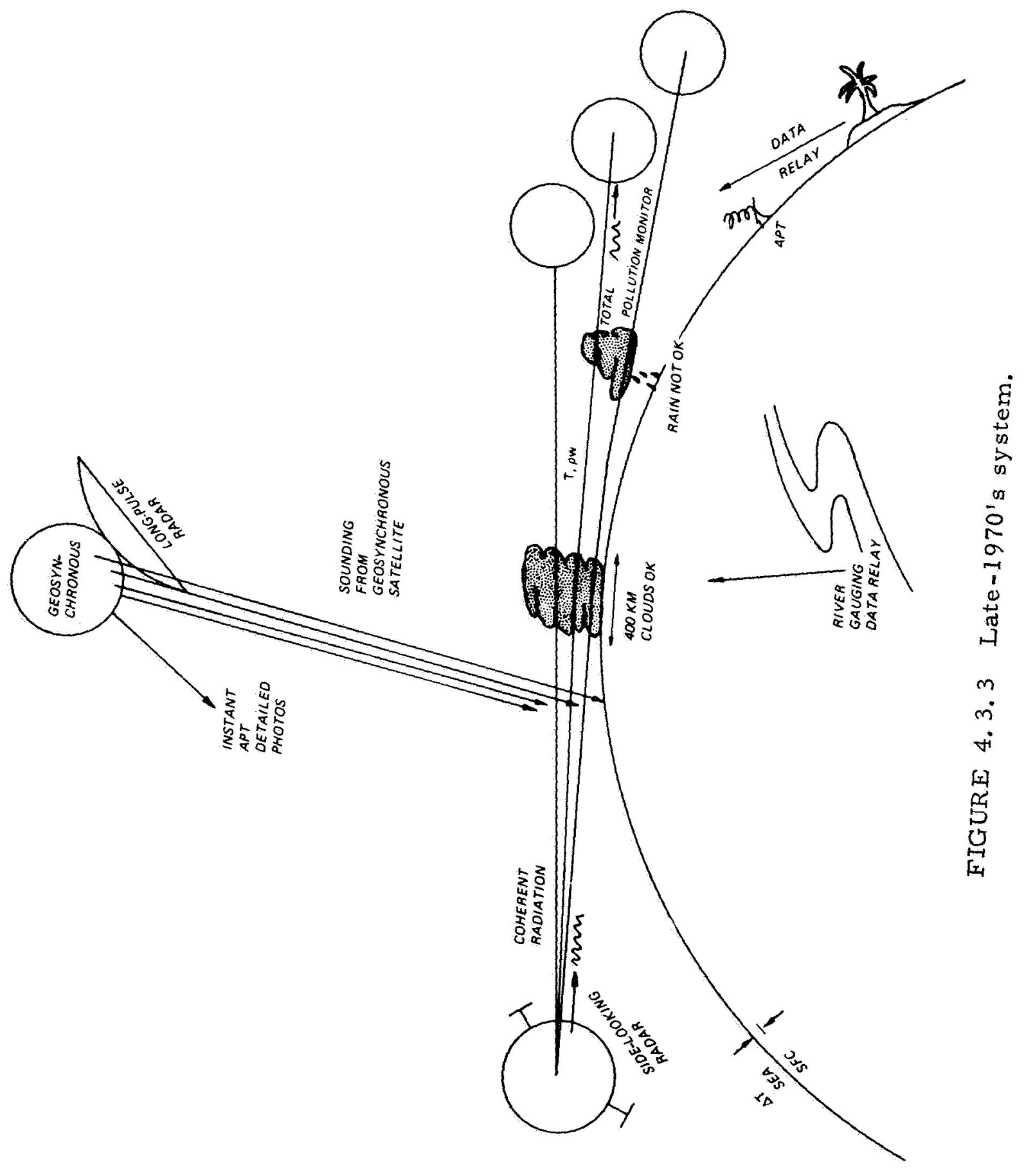




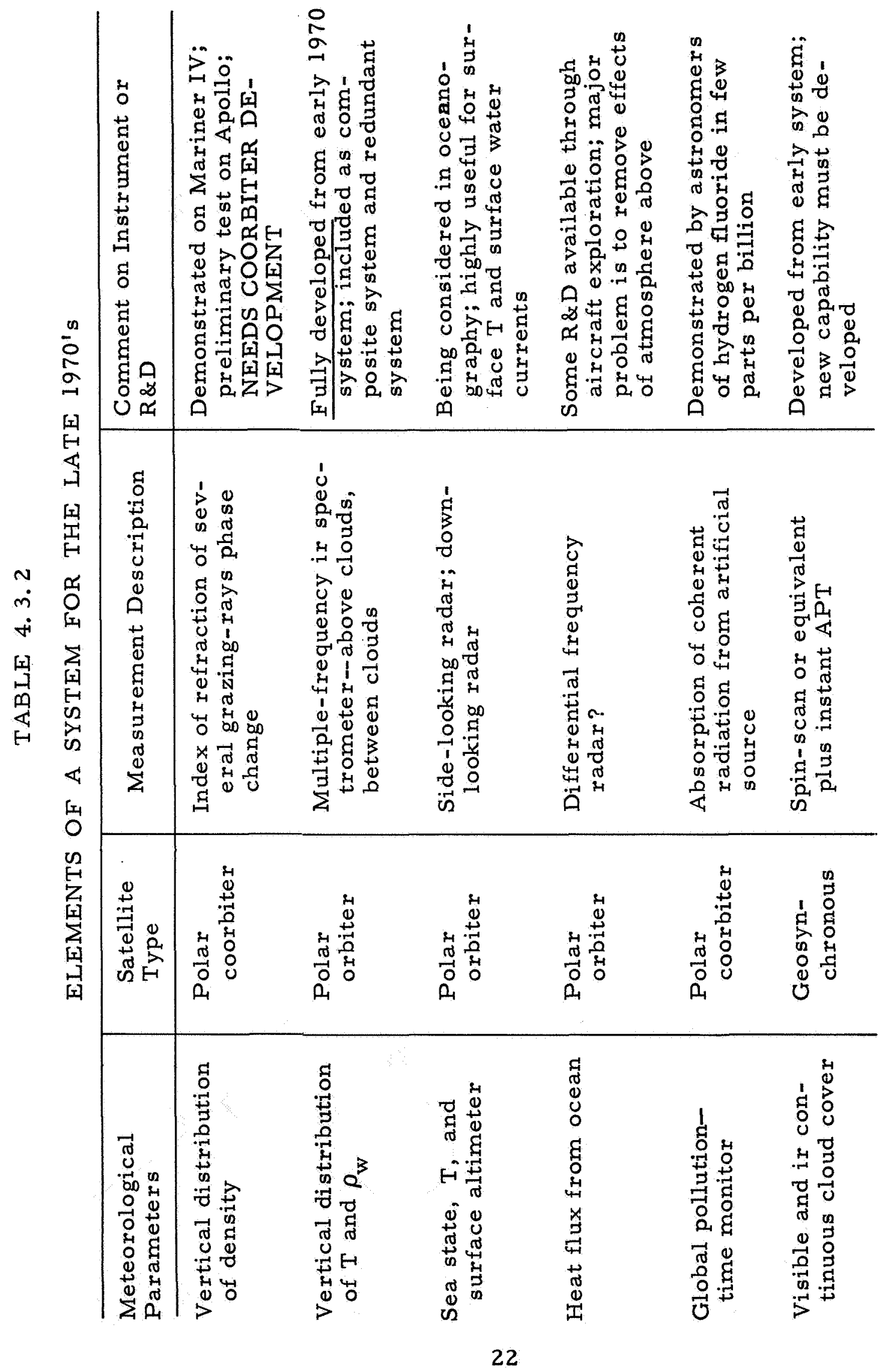




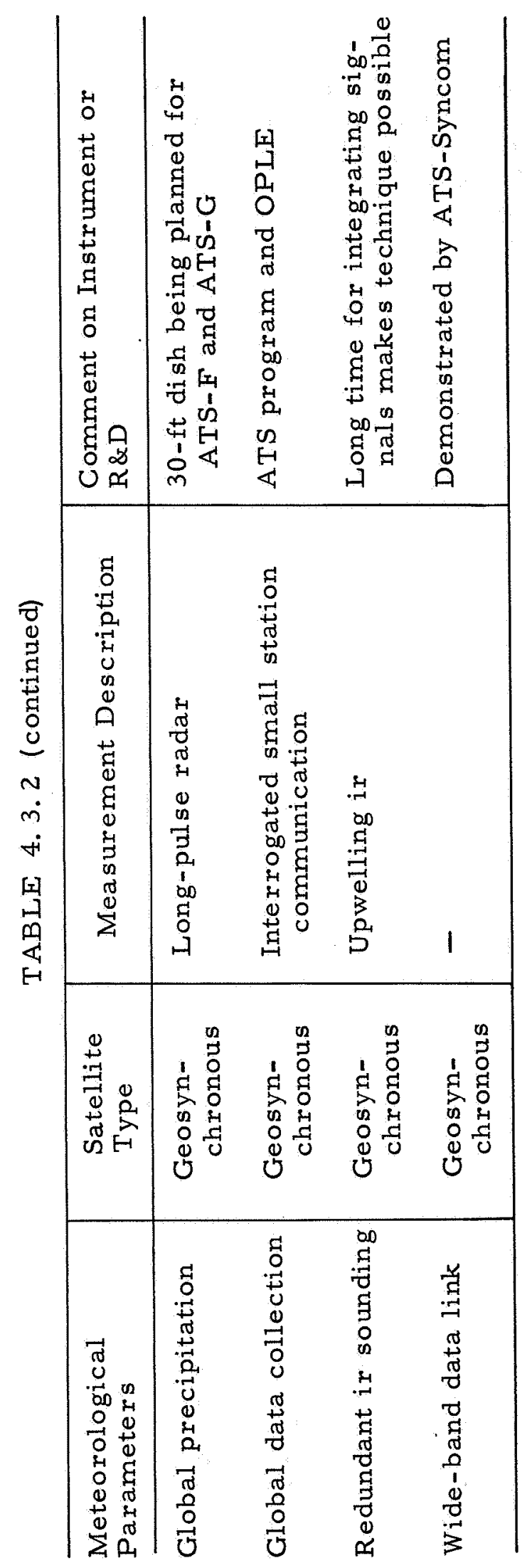




\section{4.2 Winds in the Tropics}

As we have found, winds are the fundamental dependent variable of a numerical weather-prediction system. Recent general-circulation studies have shown that at high latitudes, where the flow is quasi-balanced, the wind field is specified by the distribution of the pressure field. This is not true at low latitudes, where the vertical component of the earth's rotation is small. These same studies and the spin-scan camera pictures from ATS-I indicate a considerable interaction between the northern and southern hemispheres. Thus the measurement of the three-dimensional wind structure in the tropics is essential for the extension of numerical weather predictions to periods of a week or more. To overcome this data deficiency, our early-1970's system of observations requires a substantial balloon system. Such a system will be expensive, unwieldy, and possibly hazardous to aircraft and is likely to be unsatisfactory for routine use. Moreover, it will allow only the stratosphere to be sounded.

\section{4. 3 Density Determination by Radio Occultation}

The radio-occultation method of sounding the atmosphere deserves attention. The infrared-and microwave-sounding techniques derive the temperature structure from measurements of energy intensity. Factors in the atmosphere such as haze and cloud or water droplets in rain affect the transmission of this energy and thus degrade the measurement. One must measure these attenuations separately.

The index of refraction for radio propagation in the atmosphere is simply related to the atmospheric density, the very property that describes the atmosphere's mass distribution. The great advantage of using the index of refraction is that it affects the wavelength of the radiation passing through the medium, and, except for the ease of conducting the measurement, a weak signal or a strong signal of a known frequency yields exactly the same wavelength for a given index of refraction. Further wavelength or phase change is very much easier to measure to high precision than is signal intensity. Thus, if we could measure the index of refraction, we would have an excellent measure of the atmospheric density and we ought to be able to measure it more easily and better than by present methods.

One method of implementing the index of refraction measurements would be to use a radio-occultation scheme, which has already been demonstrated in the Mariner IV experiment to Mars. One way of applying this method to the sounding of the earth's atmosphere has been described by students at Stanford University. An extract of their report is given in Appendix D.

The method is not without its problems, among which are the need for a master and several slave satellites in orbits together; each satellite must have some station-keeping ability; the ionosphere must be considered, water vapor will cause difficulty over the surface; and the oblateness of the earth requires that several slave satellites be used. Even with these 
difficulties, the scheme is basically so attractive that $R \& D$ to establish its feasibility should be strongly encouraged. It has many attractive features:

1. It can penetrate clouds.

2. It samples the atmosphere horizontally with just about $400-\mathrm{km}$ grid-mesh volume.

3. It has low bandwidth and easy-to-handle information rates.

4. It could measure horizontal gradients, possibly even in the tropics, with great precision.

Many features of the index-of-refraction scheme could make this the workhorse sounding system of the future.

\subsection{Coorbiting Satellites}

Several of the advanced data systems suggested for the late 1970's and early 1980's require a coorbiting-satellite capability. Many new measurements can be made from a pair of platforms. We have listed only those areas of immediate interest for meteorology. Other applications immediately suggest themselves for precise geodesy-interferometer altimetry. When one of the satellite pair carries a source of coherent radiation, whether it be microwave, infrared, or visible light, many new measurements become possible. The long path lengths through the atmosphere using this configuration would allow accurate sampling of exceedingly low concentrations of those gases that are being accumulated in the atmosphere by, for example, $\operatorname{man}^{\prime}$ s increased industrial activity.

Establishing the feasibility of sensor techniques that rely on a precision-coorbiter capability deserves a high priority in NASA's plans.

\subsubsection{The Boundary Layer}

For accurate weather prediction it is necessary to know the exchange of momentum, heat, and moisture across the air-surface boundary and in the lowest kilometer of the atmosphere. Although this will eventually be predicted in the NWP system, it is a most difficult problem in meteorology and will at least require observational controls for some time. Moreover, an inventory of surface roughness and spectral emissivity, and their seasonal variation, is needed, because these quantities provide the surfaceboundary conditions for determining the air-surface exchange processes.

The exchange processes also critically depend on the vertical gradients of temperature and moisture in the lowest kilometer of the atmosphere, and their profiles in this layer should be determined in a two- or threeparameter representation. A marked improvement in the vertical resolution of the low-altitude temperature structure can be obtained by measurements in the 4. 3- $\mu \mathrm{CO}_{2}$ band, since the great dependence of blackbody radiation at these wavelengths makes this band a more sensitive indicator of the temperature structure at the warmest levels of the atmosphere, i. e., near the ground and in the upper atmosphere. An instrument for temperature sounding in this band is planned for AAP-A (SO43), together with measurements (SO 49 and SO50) in the $15-\mu$ region. SO43 also includes measurements in the high-frequency end of the 6.3- $\mu$ water band, which, again because of the strong dependence of blackbody energy on temperature, should give a 
more-detailed low-altitude moisture profile than can be obtained from measurements in the rotational water band.

Precisely because of the spectral variation of the backbody-energy dependence on temperature, the $15-\mu \mathrm{CO}_{2}$ band is more sensitive to the temperature in the upper troposphere and lower stratosphere, and the rotational water band is more sensitive to the upper-level water vapor. Thus the system in operational use in the late $1970^{\prime}$ 's should include use of all four bands in one instrument, in which selective chopping techniques are incorporated.

A preliminary experiment to test these techniques, which effectively obtains much higher vertical resolution by measuring the upwelling radiation in narrow parts of the line wings, is planned. The use of selective chopping in the $4.3-\mu \mathrm{CO}_{2}$ band will not only give high vertical resolution in the lower boundary layer $\{i$. e., the first kilometer) but also, because of the great strength of the $4.3-\mu$ band, allow the sounding to extend to about the $70-\mathrm{km}$ level, i. e., to important regions of the atmosphere about which we know very little. Only in this way will it be possible to obtain something like a 20-level sounding, which is the expected level of sophistication of NWP models at that time.

The principal defect of the infrared-sounding technique is that it provides no direct information about the state of the atmosphere below the cloudtops. This deficiency is particularly serious over large parts of the oceans, where surface observations are practically nonexistent. It can be partially overcome with the use of the measurements of cloud-top temperature and pressure by assuming a moist, adiabatic lapse-rate of temperature in the cloudy areas where the temperature distribution and cloud patterns indicate cyclonic curvature. Unfortunately, this condition does not apply to vast supplemental information about the subcloud conditions, such as surface wind speeds. These could be obtained from measurements of the sea state. In view of this, the Panel recommends the inclusion of the proposed global radar for ocean waves (GROW) experiment. This experiment seems to be sound and feasible, and the necessary weight, power, and volume could probably have been obtained by not overemphasizing the infrared program.

Moreover, it seems probable that minor modifications of the GROW system would provide the measurement of surface temperatures below the clouds during the passive phase (i.e., when the transmitter is off). These data, together with the measurement of temperature and pressure at the cloud-top, will allow a reasonable estimate of the temperature profile between the ground and the cloud-top. Because of the great importance of low-level temperature and of surface roughness for numerical weather prediction, it is strongly urged, if time permits, that the GROW experiment, modified to make the passive measurements also, be substituted in Nimbus D for the redundant infrared experiments.

The ir sounding system, while surprisingly good in clear air or above a solid cloud cover, has difficulty when it views a partly cloudy sky. When the sky cover is less than 50 percent, it is possible to get useful results, but only at the price of some accuracy and a great deal of extra trouble. 


\section{4.6 Precipitation}

Like the transfer processes at the air-surface interface, precipitation will be forecast by the NWP system. However, its measurement will also be necessary for some time as a control, since its feedback role in the energy-transfer processes is a major part of the atmospheric heat engine. Moreover, the precipitation forecast is of such obvious intrinsic importance as an end product that it is essential that its verification be obtained, in as much detail as possible, from global satellite measurements.

Early studies of the feasibility of weather radar in space were discouraging. They predicted high power requirements and low information return. However, the early studies were apparently based on direct extension of ground-based weather-radar techniques to space.

More recent estimates (see Appendix G) based on modern airborne technology suggest that useful observations of precipitation can be made on a global scale with modest weight and power consumption. One possible system, for which preliminary computations have been made, would operate from synchronous height, giving surveillance over much of the visible disk. It would require a 100-square-meter antenna, similar to the antennas to be flown on ATS-F and ATS-G. At a resolution of $75 \times 150$ miles it would be able to detect rainfall of $1 \mathrm{~mm} / \mathrm{hr}$ with an excellent signal-to-noise ratio. Power consumption would be somewhat greater than $60 \mathrm{~W}$.

Most of the significant rainfall of the earth occurs at rates in excess of $1 \mathrm{~mm} / \mathrm{hr}$; showers at higher rates tend to cover a proportionate fraction of the area. The nature of the rainfall can be assessed from simultaneous pictures. Thus, a radar of this lescription would be excellent for our stated objectives. The rainfall data would be useful for heat-budget studies, for forecast verification, for hydrologic studies, and for global climatology.

Rainfall can also be monitored by radar aboard a polar-orbiting satellite. Power and antenna requirements are, of course, smaller. However, the interaction between the erratic occurrence of rainfall and the infrequent sampling provided by the polar orbit is not as desirable as the continuous surveillance provided at synchronous height. Convective precipitation in particular may be poorly sampled.

Since the radar at synchronous height gives the rainfall integrated over a meteorologically suitable area, seen at a reasonable and constant angle, and gives as well a temporal history leading to global rainfall distribution, we feel that priority should be given to development of a synchronous satellite rainfall radar.

The Panel urges inclusion of rainfall radar on ATS-F and/or ATS-G if it should appear to be at all feasible. Feasibility and design studies should be given early consideration. 


\section{5 Other Related Observations}

A few types of observations related to other disciplines may become available as by-products or small extensions of meteorological observations. Their importance will be described in the reports of other Panels. Conversely, observations directed toward other disciplines may be of major value in meteorology.

\subsubsection{Satellite Altimetry}

The height of the satellite above the sea surface, and thus the relative local height of the sea, may be found by precision vertical radar. Possibly the sea height can be found by an extension of the radio ranging required to establish distance and direction of line of sight between coorbiting satellites used for occultation measurements.

The height of the sea is related to the acceleration of gravity and the tides. Once these known effects are removed, the remaining gradients determine surface ocean currents. These currents transport substantial quantities of heat from the tropics to temperate latitudes at time scales long in comparison to atmospheric transport processes. The behavior of these currents has long been suspected as playing a key role in the control of longer-term weather trends.

\subsubsection{Temperature Difference across the Sea Surface}

The bulk of the energy that drives the atmosphere is added as heat and latent heat from the air-sea interface. Specification of the air-sea exchange on a global basis is thus of as great importance to meteorologists as to oceanographers. Development of suitable techniques, either as extensions or refinements of ir or microwave observations, is required for both dis ciplines.

\subsubsection{Manned Spacecraft Support of Special Area Studies}

Meteorological research frequently involves concentrated "area studies, " where the meteorological behavior of certain characteristic areas is intensively observed for limited lengths of time. The resolution of the observation network is far finer than normal for meteorological practice. Space support of these area studies will, of course, come from the systems we have described in this report. However, the manned space program offers opportunities for exceptionally close support of these area studies. The instrumentation required need not extend beyond that already contemplated for use in earth-resources evaluation. Thus, the basic requirement is close coordination between meteorological research programs and the manned space program. 


\section{APPENDIX A COMMENTS ON DOCUMENT NASA SP-142, "A SURVEY OF SPACE APPLICATIONS"}

The Panel has reviewed NASA's plan in meteorology as laid out in "A Survey of Space Applications." It welcomes the diversion of NASA activity in meteorology toward the global observing system and toward the satisfaction of the diverse requirements of operational and research meteorology. At the same time, the Panel suggests that it is now possible and desirable to change the emphasis of those parts of the program more directly related to the world weather systems. Specific and organized attention should be given to assembling a complete set of techniques to sound all parts of the atmosphere, both in cloud-free and cloudy skies, and to the measurements in support of energy-transport determination at the lower boundary of the atmosphere.

The following comments are made with respect to the appropriate sections of the "Survey."

\section{A. 1 Weather Observation and Prediction}

\section{A.1.1 Wind Measurement}

The cost, safety hazards, deployment, and flight problems associated with constant-level balloons suggest that their use be considered only for the stratosphere, principally the tropical stratosphere where wind information or other observations that might obviate its necessity will not be otherwise available.

Alternate wind-measuring techniques are urgently needed in the troposphere. Wind inference from cloud motion observed between successive pictures from synchronous height will be a partial solution, but objective measurement is obviously more desirable.

Certain microwave and radar techniques offer hope here. A radar system, operated to obtain sea state for oceanography, can also define surface wind speed (not direction) to about 5 knots; the radar may be unaffected by clouds. The feasibility of such systems and the utility of their wind observations for numerical purposes should be investigated promptly. 
A. 1. 2 Imaging Infrared and Radar, and Atmospheric Sounding, from Synchronous Height

In the selection of ir, microwave, and radar systems for development, the unique properties of the geosynchronous orbit should be stressed. Excellent spatial resolution may be achieved because of the availability of long averaging times to improve signal-to-noise ratios. ATS-I has demonstrated adequate platform stability for any required resolution. The Panel supports proposals to develop, for ATS, an ir imaging system similar in principle to the spin-scan camera and recommends detailed study of the possibility of doing ir sounding as well as radar detection of precipitation from synchronous height.

\section{A. 1. 3 Heat Flux in the Boundary Layer}

Space techniques for measuring the transport of heat, sensible and latent, from surface to atmosphere need special attention to complete the observational base for extended weather prediction. Some hope exists for measurement of the gradient of temperature across the topmost millimeter or so of the ocean, by multispectral ir or microwave radiometry. Since correction for atmospheric effects on the radiation spectrum appears essential, it is probable that such a surface-gradient instrument would be part of a more general atmospheric sounding and oceanographic survey system.

\section{A. 1. 4 Coordination of Activities}

Meaningful coordination of NASA meteorological-satellite activities should be maintained with the international meteorological-research-anddevelopment activities represented by GARP, including the planning of experiments such as TROMEX and GLOMEX. Good coordination will lead to more rapid integration of satellite observations into the normal routine of global forecasting and more rapid progress toward the goal of useful longrange forecasting.

\section{A. 1. 5 Communications and Control}

Continuous viewing of mesoscale weather features from synchronous altitude for short-range forecasts will require an entirely new set of communications between satellite, ground station, satellite command, and data users. The data must arrive at the data user within minutes of acquisition on a time cycle and spatial resolution that depend upon the nature and severity of local weather events.

We envisage satellite data transmission to a control center equipped with devices for rapid processing and display and manned by a team of meteorologists and satellite-control engineers. Data would be relayed from the control center through a multichannel repeater system on the observing satellite or a nearby communication satellite to a simple terminal, perhaps an APT terminal, of the data user. The multichannel feature permits geographic segregation of data so that receiver bandwidth can be limited. 
Maximum utility of such a system would occur when geographically concentrated data taking is programmed at the satellite by the meteorologist at the control center. This class of operation requires development of the entire man-machine complex of which the observing sensor is an integral part--basically, a space extension of man's senses.

Development of such control and communication capabilities, integrated with sensor design, will take time and effort and should be an evolutionary process. To meet the challenge of continuous viewing, we urge the establishment of an experimental data communications and control center to operate with the meteorological experiments of the ATS geosynchronous satellites. Exercises of this facility will lead to the more definitive operational center to operate with the synchronous operational meteorological satellite (SOMS).

\section{A. 2 Weather Modification}

\section{A. 2. 1 Space Applications}

The potential role of satellite observations in weather modification seems to be (1) to aid in the prediction and location of suitable weather situations requiring modification and identification of the areas of instability permitting such modification, (2) the assessment of the modification achieved as well as of any subsequent unintended effects, and (3) monitoring of the atmosphere for completely inadvertent weather modification including, perhaps, long-term monitoring of the concentration of $\mathrm{CO}_{2}$, hydrocarbons, and other major pollutants. Most of the se capabilities fall within the scope of the observation program we are recommending; specific techniques should be developed to extract the information required and to provide the means of accurate calibration needed for monitoring long-term changes in atmospheric composition.

\section{A. 2.2 Delivery of Seeding Agents}

We question the idea of using satellites as delivery vehicles for seeding materials. On the other hand, the development of an inexpensive, frangible sounding rocket may lead to an equally economical and acceptable method of delivering substantial payloads of seeding agent to appropriate cloud heights. Recent Soviet research indicates that use of such a delivery vehicle may lead to substantial increases in weather-modification capability; silver iodide that has absorbed a liquid water coating in rising from a ground generator through a rainy atmosphere requires far more supercooling for activation than does silver iodide released directly into an environment of supercooled water droplets.

\section{A. 2. 3 Coordination of Activities}

We recommend that NASA establish liaison at the working level with agencies involved with stimulation of precipitation, hail and lightning suppression, hurricane modification, and monitoring of atmospheric constituents to consider the specific role that satellites may play in the future operations 
of those agencies. Growing awareness on the part of the meteorological community of the power and potential of satellite observation can now make such dialogue fruitful.

\section{A. 3 Satellite Observation of Air Pollution}

\section{A. 3. 1 Community Surveys}

The most important problem facing people concerned with air pollution is preventing the emission of pollutants at the source. Of course, it is true that it will never be acceptable, for reasons of both economics and convenience, to eliminate completely the emission of pollutants from any populated or industrial area. Air-use management depends largely on accurate and continuous knowledge of the chemical and physical properties of the air under consideration on whatever time-and-space scale is appropriate.

It must be recognized that the pollutant concentrations in most smog rarely exceed one part in a million parts of air. The detection and measurement of these pollutants are therefore difficult under the most favorable circumstances. Attempting to identify and measure them from satellites represents exceedingly unfavorable circumstances. Pollution is generally most acute when pollutants are confined in thin layers near the surface by restricted vertical mixing in the atmosphere. The satellite thus views the pollution through the thinnest dimension. Furthermore, the coexistence of many gaseous and particulate pollutants both in the smog and in the relatively clear but extensive air above complicates measurements from satellites. Thus the line of sight from the satellite to the ground must pass through many layers of the atmosphere, which, integrated through the whole atmosphere, contain substances that may interfere with the desired measurements.

It appears that satellite measurements on this scale are not warranted in competition with ground-based determinations, assuming present needs and technology. At best, results from satellites would be of a supplementary nature. Likewise, high-resolution photography can provide evidence of high particulate pollution, but the results are of limited quantitative value.

\section{A. 3. 2 Need for Spectroscopic Survey}

By far the most promising techniques for making such measurements from satellites are spectroscopic and involve all regions of the electromagnetic spectrum. However, the specialized application of these techniques for these purposes has not been developed. Such a study might start by examining the infrared spectra of polluted atmospheres from the ground, using a high-resolution spectrometer (0.1 wave number) and the sun or clouds as the radiation source. "Windows" in the 1 - to $12-\mu$ region would be most important. Three or four persons would be involved, and the total cost would be about $\$ 200,000$.

If such a study showed that detection from a satellite is feasible, a decision would have to be made as to whether a satellite is in fact an appropriate platform from which to make the observations. 


\section{A. 3.3 Local Resources}

The identification and monitoring of individual sources may be more feasible and more desirable than area studies such as discussed in Section A. 3. 1. This is because of the higher concentrations and the high temperatures (and thus higher emissivities). Again, sensor development and groundbased evaluations must precede any crash programs of satellite measurement, except for direct photography.

The results of such monitoring could be used for policing.

\section{A. 3. 4 Global Contamination}

There are many indications that man's activities are rapidly increasing the concentration of various contaminants in the atmosphere as a whole. Examples are carbon dioxide, sulfur dioxide, particulate material, and probably carbon monoxide and methane. Even though these are trace materials, they can markedly affect the physical and chemical nature of the atmosphere. For example, increasing amounts of carbon dioxide may tend to increase surface temperatures, and increasing amounts of particles may tend to decrease surface temperatures.

Satellites seem to be particularly appropriate for worldwide monitoring of atmospheric pollutants because of their global coverage and ability, where desired, to integrate over time and space.

Fortunately, it appears possible to avoid the technical problems mentioned earlier by utilizing the composition of the stratosphere and upper troposphere as an indicator for global pollution. In addition to worldwide distributions, the vertical profiles of individual contaminants in the upper troposphere and stratosphere would provide information on the ultimate fate of the pollutants.

Since this large-scale pollution is continuing to increase, it seems feasible to establish a continuous program of monitoring. Of course, programs currently exist for making such measurements (particularly with respect to $\mathrm{CO}_{2}$ ); but, these cannot hope to achieve the coverage possible from satellites, either spatially or with respect to a large number of substances. Whereas the data-handling problem is large for multiple groundbased stations, methods do exist for the satellite case.

Besides being desirable, the global reconnaissance of pollutants above about $5 \mathrm{~km}$ appears to be within the reach of present technology. The type of measurement envisaged involves both source and receiver of eletromagnetic energy. Ground or coorbiting satellite-borne light sources and orbiting receivers merit serious consideration. Also, direct emissions from pollutants may well provide useful information. Inasmuch as none of this sort of instrumentation currently exists, a developmental program and ground-based testing will be necessary prior to the initiation of actual satellite measurements. A serious study of the emissions from the atmosphere would be a useful first step in a developmental program. 


\section{A. 3.5 Weather Prediction}

An extremely useful application of satellites for overcoming airpollution problems would be their constituting part of a weather-prediction system that would make it possible to predict with great accuracy the occurrence of meteorological conditions conducive to the accumulation of air pollutants in specific areas. The predictions would not have to be of long range; two or three days would be enough. But the accuracy with regard to both intensity and occurrence date would have to be extremely high. Acute episodes of air pollution that have resulted in thousands of deaths have occurred in London, New York, the Donora Valley in Pennsylvania, and elsewhere. Predictions such as those just described would make it possible to evacuate or protect cardiac and respiratory cripples, who constitute most of the casualties during such acute air-pollution episodes. Furthermore, such prediction would be used to increase controls during pollution-accumulation periods.

\section{A. 3.6 Conclusions}

It thus appears that satellite measurements are of marginal use in determining community air pollutants, are somewhat more promising in policing individual sources of pollution, and have the greatest promise for measuring global contamination. At least as great a contribution to airresource management could come from general improvements in meteorological forecasting.

\section{A. 4 Standard Atmosphere}

The standard atmosphere is under consideration by the Committee on Space Research (COSPAR). An active discussion is under way concerning the distribution of helium and hydrogen in the upper atmosphere. We recommend that the COSPAR activities in this area be followed closely. Any new activity diverted toward standard-atmosphere definition should be postponed pending clarification of this situation. 


\section{APPENDIX B PROGRAM COSTS}

An illustrative system consisting of four geostationary meteorological satellites, one sun-synchronous polar-orbiting satellite, and associated ground and airborne equipment is described, and estimates of costs for a 3-year R\&D period and a 4-year proto-operational period are made.

\section{B. 1 General Considerations}

Cost estimates (Table 3.4. 1) were based on the following considerations:

1. Primary objectives of the cost-benefits methodology were to identify the major cost components of the system hypothesized by each technical panel and to maintain consistent coverage and treatment of these cost components among the several technical panels. Hopefully, the pursuit of this objective served to make more comparable the system costs presented for each panel.

2. Costs were estimated only to the detail deemed necessary to permit program comparisons and evaluations on a consistent basis.

3. This costing process reflects neither the extensive nor the intensive tradeoff analyses that might be considered for each system. Furthermore, costs (and quantifiable benefits) were not discounted, nor was the impact of the inflation question specifically addressed in view of the approximate nature of the estimates. In short, although costing was performed within a relatively consistent framework, the dollar quantities (like the system configured) must be viewed as approximate.

4. Generally, the elements included in the costing procedure were incremental costs only, i. e., those costs that would be incurred by implementing the hypothetical satellite system. It is important to note, however, that the estimates presented do not include the following major cost items that undoubtedly would be incurred because of implementation of a particular system:

a. Costs incurred by user agencies for education or extensive training and upgrading of personnel and procedures

b. Costs of analysis and interpretation (e. g. , photographic interpretation) of the data received by user agencies

c. Any costs incurred by individuals or organizations "downstream" from the user agencies, e. g., costs to a farmer 
to revise his farming methods or to replace machinery due to new information provided by the satellite system

5. The primary functional categories were divided into collecting data from space, and processing and distributing these data to user agencies:

a. Space-segment costs

(1) Spacecraft (satellite) and sensors

(2) Launch (launch vehicle, launching-pad costs)

(3) Ground system (in general, ground stations, communication links, and tracking used to monitor, track, and control the satellite)

(4) System management and administration of the space system

b. Processing-and-distribution-segment costs

(1) Spectral-signature analysis and ground truth

(2) Ground system (in general, ground stations, communication links, and tracking needed to read out imagery and other information collected)

(3) Processing (equipment for processing and organizing collected data into a form suitable to the user agencies, and distributing the data)

(4) System management and administration of the processing and distribution segment

(5) Platform equipment, such as buoys, balloons, and various types of ground collection-transmitter stations

\section{B. 2 Specific Considerations}

Cost estimates are made under the following assumptions:

1. Time frame: Three years $R \& D$ followed by 4 years proto-operational.

2. Spacecraft (satellite)

a. Near-polar orbiter with 1 -year life, costing $\$ 4.8$ million each. Provides an ir stripmapper and an ir sounder. One in orbit at all times. Five launches required.

b. Geosynchronous satellite with 2 -year life, costing $\$ 9$ million each. Four to be in orbit at all times. Two satellites will be launched with each launching vehicle. A total of five launches required. Contains a spin-scan color camera, polarizer, ir imager and sounder, and communications equipment to collect data transmitted from the balloon platforms.

3. Launch vehicles

a. Thor-Delta type of vehicle is used to launch polar orbiters. The launch vehicle is priced at $\$ 3$ million. Launching-pad operational costs are $\$ 2$ million. 
b. One Atlas-Centaur type of vehicle is used to launch two geosynchronous satellites at a time. The launch vehicle is priced at $\$ 9$ million. Launching-pad operational costs are $\$ 6$ million.

4. Contingencies

a. One spare satellite and launch vehicle are provided for the nearpolar orbiter. Their launching costs are included in the total costs.

b. A total of five launches and ten satellites is provided for the geosynchronous satellite in order to keep four in space at all times.

5. Other

a. Launch-vehicle $R \& D$ and test and integration of the geosynchronous satellite total $\$ 18$ million, although $\$ 10$ million would suffice if the $R \& D$ and test and integration were performed as piggyback appendages to an ATS-E type of program.

b. Minimum of two ground stations needed with the geosynchronous segment.

c. Assumed that any nominal $R \& D$ needed on the polar segment is included in current and future NASA-ESSA budgeted expenditures.

d. Launch of a GROW polar satellite would increase launch-vehicle and launch-pad costs by $\$ 5$ million per year for 4 years, plus $\$ 5$ million per GROW satellite. In short, over the 4-year protooperational phase, inclusion of GROW (with one spare) would increase the cost by $\$ 50$ million.

e. Balloon configuration is indefinite because of uncertainties regarding: the number required (from 1000 to 3500); expected lifetime (from 3 months to 6 months); and the cost per balloon, including deployment (from $\$ 1000$ to $\$ 5000$ ). Hence, the following range is provided:

(1) LOW cost ( 1000 balloons with 6 -month life @ $\$ 1000$ per balloon) = \$2 million per year

(2) MIDDLE* estimate (1000 balloons with 3-month life @ \$5000 per balloon) = \$20 million per year

(3) HIGH cost (3500 balloons with 3-month life @ $\$ 5000$ per balloon) $\quad \$ 70$ million per year

6. Data interpretation will be performed by photo interpreters and other trained persons now engaged in agencies.

*The middle estimate was used in the analysis presented in Table 4. B. 1 . 
TABLE 4. B. 1

METEOROLOGY-SATELLITE SYSTEM---SEPARATE DISCIPLINES

COSTING ESTIMATES

(MILLIONS OF DOLLARS)

SPACE SEGMENT

Spacecraft (satellite and

sensors)-near-polar

Launch (vehicles, pad costs) nearpolar orbit

Spacecraft-geosynchronous

Launch-geosynchronous

Ground system (station, network, tracking)

Systems management

TOTAL - SPACE SEGMENT

\section{PROCESSING AND DISTRIBUTION \\ SEGMENT}

Signature analysis and ground truth

Ground system (station, network)

Processing (equipment, data handling, film, distribution)

Systems management

Balloons

TOTAL - P\&D SEGMENT

GRAND TOTAL

\begin{tabular}{|c|c|c|c|}
\hline 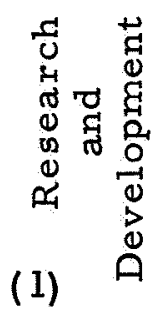 & 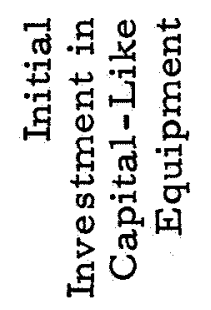 & 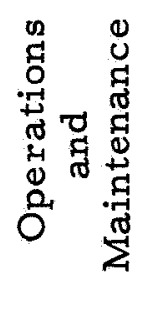 & $\begin{array}{c}7 \\
\stackrel{\pi}{\pi} \\
0 \\
0 \\
F\end{array}$ \\
\hline $\begin{array}{r}8 \\
18 \\
1\end{array}$ & $\begin{array}{l}(2) 24 \\
\text { (2) } 15 \\
90 \\
45 \\
8\end{array}$ & $\begin{array}{l}\text { (2) } 10 \\
30 \\
30 \\
\begin{array}{r}20 \\
5\end{array}\end{array}$ & $\begin{array}{r}24 \\
25 \\
98 \\
93 \\
29 \\
5\end{array}$ \\
\hline 27 & 182 & 65 & 274 \\
\hline 5 & 2 & $\begin{array}{l}\text { (3) } 14 \\
\text { (3) } 46 \\
20 \\
80\end{array}$ & $\begin{array}{l}14 \\
48 \\
20 \\
85\end{array}$ \\
\hline 5 & 2 & 160 & 167 \\
\hline 32 & 184 & 225 & 441 \\
\hline
\end{tabular}

(1) Includes integration, engineering, and testing.

(2) These costs are presently funded and are expected to continue being funded in future ESSA budgets.

(3) Of this total of $\$ 80$ million, $\$ 44$ million is presently funded and is expected to continue being funded in future ESSA budgets. 


\section{APPENDIX C ECONOMIC BENEFITS}

The proposed meteorology-satellite system is configured to provide ultimately a relatively accurate 5- to 7-day weather forecast-comparable in accuracy to the currently available 1- to 2-day forecast. The 3- to 6-day foreshortening in weather prediction will yield substantial economic benefits (both cost savings and revenue increases) to several weather-sensitive activities and industries in the United States (and throughout the world). However, the Panel did not quantify and translate these benefits into " $\mathrm{x}^{\text {" number }}$ of dollars per annum by specific industrial sectors-and for several reasons.

First, inadequate and insufficient research has been directed to this critical question: What are the quantifiable dollar-benefits that would accrue to selected industrial sectors in the United States from a system that would provide a 5- to 7-day weather forecast with accuracy comparable to the currently available 1- to 2-day forecast within a two-county-wide area?

Second, to quantify and then proceed to sanctify in public print numbers that are at best tenuous, arguable, and unsupported by solid research serves two purposes-confusion and disenlightenment.

Third, insufficient time and inadequate resources were available during the two summer study sessions to undertake the necessary research effort required. The effort, time, money, and personnel required would be substantial. Hence, the Panel decided to direct its limited energies toward a more limited and realistic objective, namely, the subjective appraisal in certain benefit areas.

Substantial benefits would accrue to society were an accurate 5- to 7-day weather forecast forthcoming. For example:

1. More efficient management of air, highway, and water-traffic routing and scheduling

2. Decreased spoilage of perishable commodities in transit or at terminal facilities

3. More efficient scheduling of on-site filming in the movie industry

4. Improved planning of recreational activities-in fact, some sporting events

More significant, however, are the far higher economic benefits that would flow to the following industrial or public sectors:

1. Agriculture (e.g., saving an unnecessary reseeding, fertilizing, or spraying operation, or accelerating a harvest) 
2. Construction (e.g., optimum scheduling of the work force, materials, and machinery at various sites)

3. Water management and conservation (e. g. , flood control (advance warning, and where possible, avoidance), and irrigation (saving an unnecessary irrigation of a vast area))

4. Public utilities (electricity and gas)-more efficient policy of facility repair, maintenance and replacement, and switchover of capability*

Some research effort has been directed at identifying and quantifying the benefits in a few of the areas outlined above-but without marked success thus far. What is needed in this economic benefit area are user-oriented case studies in selected sectors that address the specific question raised above. Some examples of possible approaches are contained in work done by the Travelers Research Institute (construction and weather), the Planning Research Corporation (agriculture and weather) and the Westinghouse analysis of earth resources. Though these studies did not address the specific question raised here, they were commendable in the approach and methodology adopted. Each of the se studies employed a user-oriented approach--in other words, information was obtained through interviews from users of the technical data concerned. Going to the user for his evaluation of, say, a 5- to 7-day weather forecast seems quite logical and necessary. An expert user's opinion should prove more reliable and valid than a percentage " $\mathrm{x}^{\text {" or }}$ " $\mathrm{y}$ " that was derived by sheer speculation! On the other hand, any research organization should carefully weigh the implicit biases and prejudices that are contained in statements received from a user group.

In short, the Panel, together with the cost-benefit consultants, advocates an increase in the time, money, effort, and personnel required to undertake benefit analyses that address the question posed originally. The Panel has not shirked its task-but, rather, focused attention on an approach to solve the problem. The Panel believes a valuable service was performed in avoiding the generation of still another set of tenuous, fictitious, and unsupported numbers of dollars.

Even though not quantified, the Panel does believe the benefits that would be received from a valid 5- to 7-day forecast would be sufficiently substantial to warrant undertaking the first phase of the recommended program.

* See the Pennsylvania Power and Light Company letter appended to this discussion. 


\section{PENNSYLVANIA POWER \& LIGHT COMPANY}

117 EAST BROAD STREET, HAZLETON, PA. 18201

TELEPFONE: 454-6641

July 21,1967

Dr. James B. Hobbs

Little Harbor Farms

Woods Hole, Massachusetts 02543

Dear Sir:

In response to your request for an answer to the question - "What are the economic benefits for power companies for an accurate seven (7) to fourteen (14) day weather forecast?" discussed in your conversation with Mr. C. S. Scapellati of this company, I have prepared the following comments.

I feel that before one can list the economic benefits which a power company may derive from this method of weather prediction, certain basic terms must be specifically defined. The word "accurate" in the above statement implies, by definition, exactness or correctness in predicting weather parameters for a period from 7 to 14 days. Since the forecasting of daily loads would be one of the main benefits derived from accurate weather forecasting, we are definitely interested in accurate forecasts; as an example We are interested in temperature forecasts for the following day to be accurate within 1 or 2 degrees and we require the prediction of the time of the passage of a frontal system to be accurate within approximately 1 hour. Should the use of weather sateliites enable meteorologists to predict these and other weather parameters to this degree of accuracy, it would aid immeasurably in the prediction of day-to-day load forecasts. Increased accuracy in these forecasts, in turn, provide increased reliability and reduced production costs resulting from improved scheduling of generating capacity.

The power company is also interested in long-range weather forecasts ( 7 to 14 days) to aid in the scheduling of maintenance outages of both generating equipment and/or transmission facilities on its system. Once again, the accuracy of these long-range weather forecasts must be investigated, since complete reliance on a long-range weather forecast and the resultant scheduling of maintenance could prove economically unsound and could be catastrophic to the system should these long-range weather forecasts be inaccurate by a factor of 1 or 2 days. However, should these forecasts prove to be accurate as defined above, considerable economic benefits can be realized if maintenance is scheduled in an optimum manner.

One of the greatest advantages to be gained from an accurate 7 to 14 day weather forecast would be in the scheduling of hydro electric generating statigns. Since the scheduling of generation on run-of-river and pumped storage

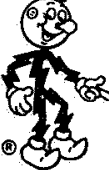

An investor-owned electric utility in the service of the public 
plants is predicated on predicted river flows for a period of a week or more, relatively accurate rainfall estimates for a period of 7 to 14 days would be advantageous in obtaining the maximum economic benefits from the water available. This would apply to a somewhat lesser degree to a storage-type hydro electric station, but in the instance of relatively high or low lake elevations, accurate 7 to 14 day rainfall estimates could result in definite economic benefits and improvement in customer relations for the company involved.

Thus far I have limited this discussion mainly to the question of the possible economic benefits which a power company could derive from accurate long-range weather forecasts. Another facet of this picture should deal with the benefits derived in the field of public relations. If accurate forecasts of very adverse weather conditions, such as hurricanes, or other disastrous weather conditions be predicted, the company could take positive steps such as: (1) marshalling of materials and men, (2) knowing the path of the storm, personnel could be shifted from one area to another, and (3) maintenance outages of equipment could be cancelled. These steps would result in improved continuity of service, thereby increasing the customer's confidence in the power company and generally improving public relations.

In sumary, then, I feel the main advantages ensuing from an accurate 7 to 14 day weather forecast would be in the fields of daily load forecasting, scheduling maintenance, economic scheduling of hydro electric stations, scheduling of construction crews, making preparations for very adverse weather conditions such as the scheduling of crews, the dispatching of materials, and the evaluation of the potential damage to an electrical system, and, finally, the advantage gained by notification to the public of potential troubles existing on an electrical system. It should be realized, of course, that an accurate 4 to 5 day weather forecast would provide the majority of these same advantages to an electrical system.

There has been no effort to attach a dollar value to the economic benefits evolving from accurate 7 - 14 day weather forecasting due to the following reasons:

1. It is felt that a dollar evaluation should encompass a cross-section of electrical utilities throughout the United States. One company's evaluation could be grossly mis leading.

2. A dollar evaluation revolves around the definition of the word "accurate" as previously indicated.

3. A dollar evaluation of the benefits gained from improved customer relations resulting from increased system reliability is a rather nebulous one, but perhaps the most important parameter affecting this evaluation. 
Should you require additional information, we will be happy to assist you in any manner possible. However, we suggest that a more complete definition of the problem be prepared prior to any future request.

Very truly yours,

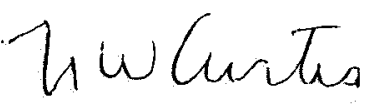

N. W. Curtis

Supt. of System Operation 



\section{APPENDIX D}

\section{A PROPOSED RADIO-OCCULTATION SYSTEM*}

A radio-occultation system is proposed, in the following sections, that propagates microwaves between two satellites so that the radio waves pass through the earth's atmosphere. The main advantage of using microwaves is that they can penetrate clouds, and it is theoretically possible to correct for any effect the cloud has on the transmission path. Also, extremely precise doppler measurements on the relative velocities between the two satellites can be made, using developed deep-space-tracking techniques.

The basic idea of the radio-occultation-satellite system is straightforward and is shown in Figure 4. D. 1 .

As the radio signal passes through the atmosphere, it is refracted, and this in turn gives rise to a change in the apparent motion between the two satellites. If all other effects that produce a doppler shift are accounted for (such as any real motion between the satellites due to perturbations in the orbit, or any other apparent motion caused by refraction due to the ionosphere and water vapor), the remaining changes can be attributed to refraction by the atmosphere, which can in turn be related to change in the atmosphericmass density.

The radio-occultation experiment can be implemented with three major subsystems: (1) a platform, (2) a radio transponder, and (3) a data-reduction center. The basic platform consists of one master satellite and six repeater slave satellites in the same highly circular polar orbit. The slave satellites are spaced so that radio waves propagating between them and the master satellite will cut the atmosphere at a number of different levels. Since intersatellite spacing is critical, all satellites will require station-keeping ability. The radio transceiver and electronics are mounted on the satellite to measure and record doppler shifts and send the data to the ground collection center. Since a doppler shift can be caused by a number of other effects besides changes in mass density, provision must be made to remove these errors from the data at a ground data-reduction center.

The performance objectives for the system are to measure mass-density profiles accurately to $\sim 1$ percent and to measure horizontal-density gradients to $\sim 0.2$ percent. The altitude at which the measurements are taken will be determined to $\pm 30 \mathrm{~m}$. With three complete systems, each grid point will be covered every $12 \mathrm{hr}$ with a grid size of $953 \mathrm{~km}$ at the equator. Six slave satellites will allow measurements to be made at five levels in the atmosphere.

*Based on Spinmap, final report, Stanford University, June 1966. 


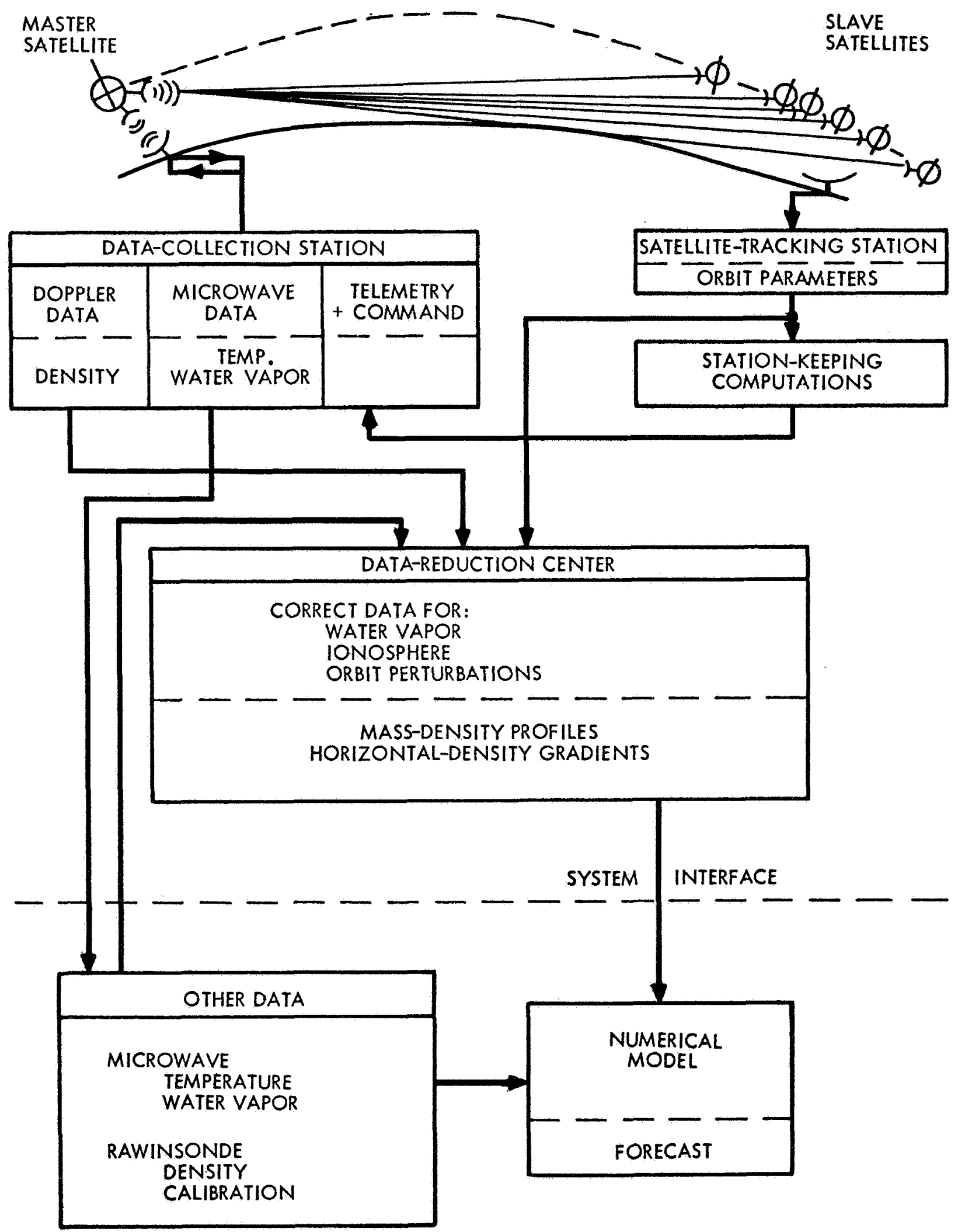

FIGURE 4. D. I Basic occultation-satellite system. 
The remainder of this section will discuss the magnitude of the effects measured and will propose a combination-satellite system capable of performing both the occultation and the microwave experiments discussed in Section 5.2.4 of the report from which this Appendix is abstracted.

\section{1 Theory of Operation}

\section{1. 1 Atmospheric Doppler Shift}

The atmospheric contribution to the measured doppler shift is due to two effects. First, the ray is retarded by the atmosphere, and, second, the ray is bent and therefore travels a longer path. Making the assumption that the atmospheric mass density is exponentially distributed with altitude allows the size of these two effects to be determined.

Assume: $\rho=\rho_{\mathrm{s}} \mathrm{e}^{-\mathrm{z} / \mathrm{H}}=1.200 \mathrm{e}^{-\mathrm{z} / 8.1}$, where $\mathrm{z}=$ altitude $(\mathrm{km}), \mathrm{H}=$ scale height $(\mathrm{km}), \rho=$ density $\left(\mathrm{kg} / \mathrm{m}^{3}\right)$, and $N=$ modulus of refraction. Since $N=$ $222 \rho+$ (water-vapor term), we have

$$
\begin{aligned}
& N=N_{s} e^{-z / H}+(\text { water-vapor term), } \\
& N=270 e^{-z / 8.1}+\text { (water-vapor term). }
\end{aligned}
$$

With these assumptions, the calculations are relatively straightforward and are covered in detail in numerous sources where the ideal nature of the atmosphere is also considered. If (see Figure 4. D. 2)

$\Delta R(h)=$ two-way retardation effect as a function of altitude,

$\Delta L(h)=$ two-way bending effect as a function of altitude,

$\Delta \epsilon(h)=$ bending angle as a function of altitude,

$\dot{\delta} \mathrm{d}=$ apparent doppler shift,

$\mathrm{h}=$ altitude of measurement,

$h_{0}=$ altitude of straight-line path,

$d=$ deviation of true path from ideal.

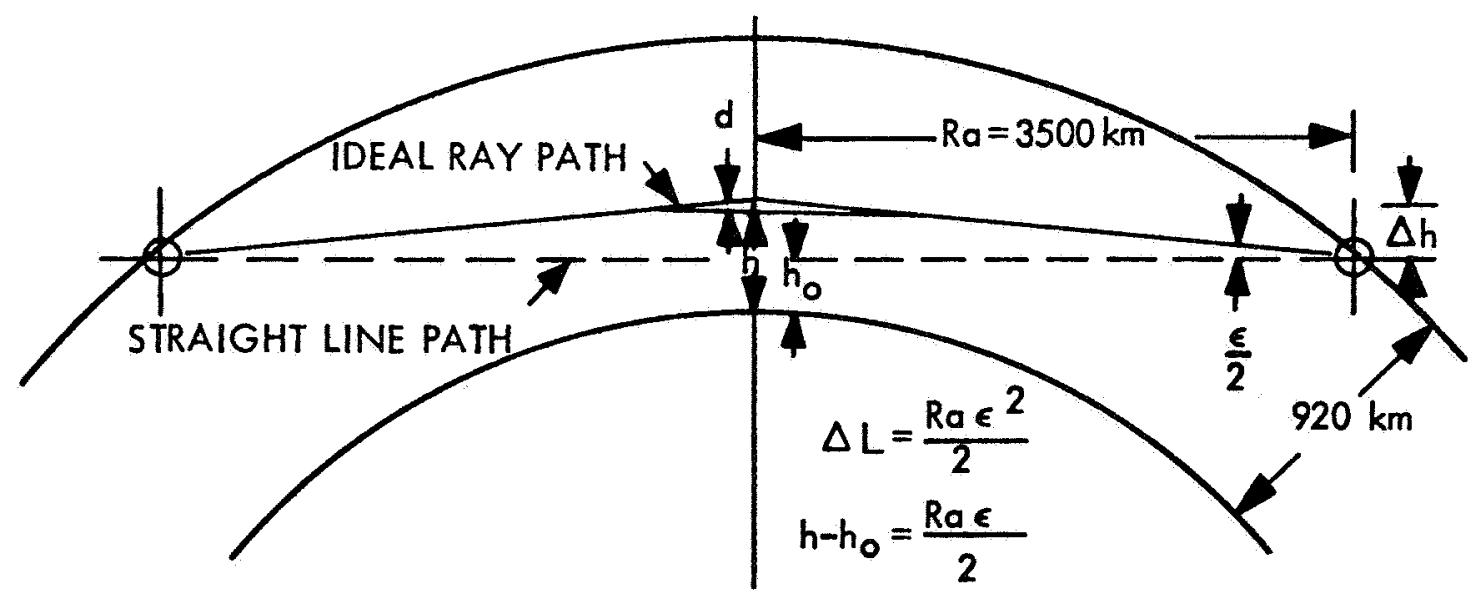

FIGURE 4. D. 2 Doppler-shift geometry. 
Then

$$
\dot{\delta} \mathrm{d}=\frac{\mathrm{d}}{\mathrm{dt}}[\Delta \mathrm{L}(\mathrm{h})+\Delta \mathrm{R}(\mathrm{h})]=\frac{\mathrm{d}}{\mathrm{dt}}\left[\mathrm{Ra} \frac{\epsilon^{2}(\mathrm{~h})}{2}+\Delta \mathrm{R}(\mathrm{h})\right] .
$$

The result is

$$
\begin{aligned}
\epsilon(h) & =2 \times 10^{-6} \mathrm{~N}_{\mathrm{s}} \mathrm{e}^{-\mathrm{h} / \mathrm{H}} \cdot \frac{1}{\mathrm{H}} \cdot\left(\frac{\pi \mathrm{RH}}{2}\right)^{1 / 2} \approx 21.5 \mathrm{e}^{-\mathrm{h} / 8.1 \times 10^{3},} \\
\Delta \mathrm{R}(\mathrm{h}) & =2 \mathrm{H}(\mathrm{h}) \\
\Delta \mathrm{L}(\mathrm{h}) \approx 348 \mathrm{e}^{-2 \mathrm{~h} / 8.1 \times 10^{3}}, & =\operatorname{Ra} \epsilon^{2} / 2=810 \mathrm{e}^{-2 \mathrm{~h} / 8.1 \times 10^{3}}, \\
\int \dot{\delta} \mathrm{d} d t & =348 \mathrm{e}^{-2 \mathrm{~h} / 8.1 \times 10^{3}}+810 \mathrm{e}^{-2 \mathrm{~h} / 8.1 \times 10^{3}}
\end{aligned}
$$

$\left[\epsilon(h)\right.$ is in milliradians, $h, \Delta R(h), \Delta L(h)$, and $\int \dot{\delta} d$ dt are in meters].

This is the total apparent-distance change satellite to repeater and back, caused by the mass of the atmosphere. At sea level

$$
\int \dot{\delta} \mathrm{d} d t=1258 \text { meters and } \mathrm{e}_{\mathrm{s}}=1.2 \mathrm{~kg} / \mathrm{m}^{3}
$$

Therefore, a $1-\mathrm{m}$ change in apparent distance is equivalent to a $1 \mathrm{~g} / \mathrm{m}^{3}$ change in mass density. The proposed doppler system operates at $5.25 \mathrm{GHz}$ and can resolve changes in apparent distance of $\lambda=4.7 \mathrm{~cm}$. Therefore, detecting a $1-m$ apparent-distance change presents no difficulties. The difficulties in the experiment arise in eliminating other sources of doppler shift and in determining the height of the measurement.

\section{1.2 Other Sources of Doppler Shift}

\section{1.2. 1 Oscillator Stability}

At the measurement frequency (5.25 GHz), assuming a practically obtainable oscillator stability of $10^{-9}$ parts per $\mathrm{Hz}$, a frequency error of $5.25 \mathrm{~Hz}$ can occur. For a transit time of $46 \mathrm{msec}$, the maximum constant doppler tracking off set will be \pm 0.25 counts. For a sample time of $30 \mathrm{sec}$, this corresponds to a negligible apparent-velocity error of $0.00050 \mathrm{~m} / \mathrm{sec}$.

\section{1.2. 2 Ionosphere}

At $5 \mathrm{GHz}$, the maximum doppler-count error due to the ionosphere was calculated to be a negligible $0.03 \mathrm{~Hz}$ (apparent velocity $=0.0017 \mathrm{~m} / \mathrm{sec}$ ). The ray is also bent by the ionosphere, causing a maximum error in determining the height of the measurement of $65 \mathrm{~m}$. If greater accuracy is necessary, these values can be reduced by an order of magnitude, since the ionospheric effect is predictable within 10 percent. 
D. 1.2.3 Water Vapor

Water vapor is the most difficult additional doppler shift to account for. The magnitude of this effect can be seen in the following calculation:

$$
\mathrm{N}=222 \rho+373,000 \frac{\left(\mathrm{P}_{\mathrm{w}} /\right.}{\left.\mathrm{T}^{2}\right)},
$$

where $\mathrm{p}_{\mathrm{w}}=$ water-vapor partial pressure in millibars $(\mathrm{mb})$ and $\mathrm{T}=\mathrm{Temper}-$ ature $\left({ }^{\circ} \mathrm{K}\right)$ or, solving for $\rho$,

$$
\rho=0.45 \times 10^{-2} \mathrm{~N}-1,680 \frac{\left(\mathrm{p}_{\mathrm{W}} /\right.}{\left.\mathrm{T}^{2}\right)} .
$$

Taking the total derivative for small changes in $\mathrm{N}, \mathrm{p}_{\mathrm{w}}$, and $\mathrm{T}$ gives

$$
\Delta \rho=\left(\frac{\partial \rho}{\partial \mathrm{N}}\right) \Delta \mathrm{N}+\left(\frac{\partial \rho}{\partial \mathrm{p}_{\mathrm{W}}}\right) \Delta \mathrm{p}_{\mathrm{w}}+\left(\frac{\partial \rho}{\partial \mathrm{T}}\right) \Delta \mathrm{T} .
$$

Table 4.D. I shows typical values for $\partial \rho / \partial \mathrm{N}, \partial \rho / \partial \mathrm{p}_{\mathrm{w}}$, and $\partial \rho / \partial \mathrm{T}$ at various altitudes of $h_{0}$.

TABLE 4. D。 1

WATER-VAPOR CORRECTIONS

\begin{tabular}{c|c|c|c|c|c|c}
\hline$h_{\mathrm{o}}(\mathrm{km})$ & $\mathrm{T}\left({ }^{\circ} \mathrm{K}\right)$ & $\mathrm{N}$ & $\mathrm{p}_{\mathrm{w}}(\mathrm{mb})$ & $\frac{\partial \rho}{\partial \mathrm{N}} \times 10^{+2}$ & $\frac{\partial \rho}{\partial \mathrm{p}_{\mathrm{w}}} \times 10^{+2}$ & $\frac{\partial \rho}{\partial \mathrm{T}} \times 10^{+2}$ \\
\hline 0 & 288.1 & 314.3 & 10.2 & 0.45 & -2.03 & 0.143 \\
2 & 275.1 & 246.2 & 4.5 & 0.45 & -2.22 & 0.072 \\
4 & 262.2 & 191.3 & 1.7 & 0.45 & -2.45 & 0.032 \\
10 & 223.2 & 92.4 & 0.04 & 0.45 & -3.34 & 0.002 \\
\hline
\end{tabular}

Table 4.D.2 shows the absolute and relative accuracy needed in the measurements of $\mathrm{N}, \mathrm{p}_{\mathrm{w}}$, and $\mathrm{T}$ to detect $\mathrm{a} \pm 1 \mathrm{~g} / \mathrm{m}^{3}$ change in atmospheric mass density. At sea level this corresponds to an accuracy of about 0.1 percent. It also shows that in order to get density measurements accurate to 0.1 percent above $h_{0}=2 \mathrm{~km}$, the water-vapor partial pressure and temperature must be known to about 1 percent. Since data of this precision will be recorded independently by the microwave radiometer on the master satellite, the contribution of water vapor to the atmosphere refractive index can be measured to the required accuracy for altitudes above about $2 \mathrm{~km}$. 
TABLE 4. D. 2

REQUIRED MEASUREMENT ACCURACY

\begin{tabular}{c|c|c|c|c|c|c}
\hline $\mathrm{h}_{\mathrm{o}}(\mathrm{km})$ & $\Delta \mathrm{N}$ & $\% \Delta \mathrm{N}$ & $\Delta \mathrm{p}_{\mathrm{w}}(\mathrm{mb})$ & $\% \Delta \mathrm{p}_{\mathrm{w}}$ & $\Delta \mathrm{T}\left({ }^{\circ} \mathrm{K}\right)$ & $\% \Delta \mathrm{T}$ \\
\hline 0 & 0.22 & 0.070 & 0.049 & 0.48 & 0.70 & 0.243 \\
2 & 0.22 & 0.090 & 0.045 & 1.00 & 1.69 & 0.50 \\
4 & 0.22 & 0.115 & 0.041 & 2.4 & 3.12 & 1.19 \\
10 & 0.22 & 0.240 & 0.030 & 75.0 & 50.0 & 22.0 \\
\hline
\end{tabular}

D. 1.2. 3 Satellite Relative Velocity

Relative velocity between two satellites in approximately the same nearly circular orbit is due to the sum of three components which are caused by orbital eccentricities, harmonics of the earth's geopotential, and small differences in orbital period. Each of these effects must be eliminated from the doppler-shift data to give an accurate picture of the change in refractive index of the earth's atmosphere.

Relative velocity due to slight eccentricities in orbits will fluctuate with time; however, it will always have the same period as the orbital period. Because there will be no component of data at this frequency, a digital filtering technique can be used to eliminate this effect.

The relative velocity due to in-orbit drift can be accurately measured by ground observations over a period of several days or it can be detected from the doppler-shift data. In the proposed system, this component of velocity will be automatically kept small by the necessary station-keeping; however, it is not negligible compared with the data, and a compensation must be made.

For the proposed polar orbits, the primary harmonic effect is due to the $\mathrm{J}_{2}$ oblateness term, which will cause a relative-velocity error as shown in Figure 4. D. 3.

Higher harmonics will also be present; however, their effect is less than $10^{-3}$ times that caused by $J_{2}$. It is proposed that this velocity be continually measured by a single repeater satellite whose ray path would never be allowed to enter the atmosphere. After this velocity is corrected for eccentricity and drift it will provide a measure of the velocity due to the earth's harmonics accurate to 0.2 percent. This measurement will also provide an independent measurement of the value of $J_{2}$ accurate to 1 part in 10,000 and much valuable information about higher order terms.

\section{1. 3 Determination of the Height of the Measurement}

To determine the minimum height of the ray, three quantities must be determined: the position of both satellites, the bending angle, and the amount that the true ray path deviates from the ideal path (see Figure 4. D. 2 ). 

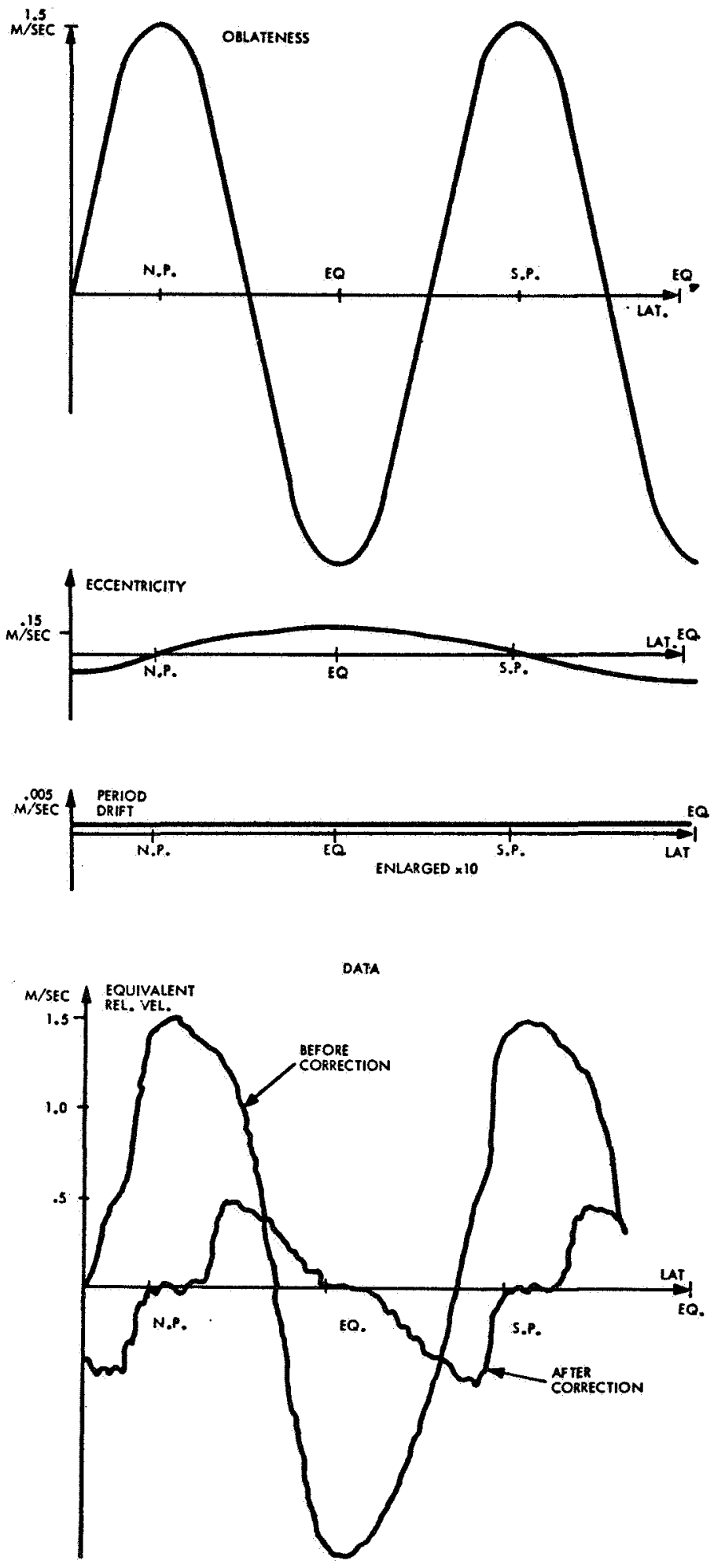

FIGURE 4. D. 3 Relative-velocity errors.

51 
The absolute position of the satellites can probably be determined to $\pm 30 \mathrm{~m}$ using doppler ground tracking plus the doppler measurement between the master and slave satellites, to calculate precisely small orbit perturbations. Since the bending angle $\epsilon$ decreases exponentially with altitude [Eq. (2)], a small change in satellite position $\Delta r$ will cause an even smaller change $\Delta \mathrm{h}$ in the altitude of the ray. For an exponential atmosphere,

$$
\Delta h=\frac{\Delta r}{1+\frac{\epsilon_{s} R_{a}}{H} e^{-h / H}}, \quad \frac{\epsilon_{s} R_{a}}{H} \approx 9.3 .
$$

The errors due to the position of the satellite should be only about $\pm 10 \mathrm{~m}$.

The bending angle $\epsilon$ can be calculated from knowledge of the position of the satellite, the total doppler shift due to the atmosphere, and an assumption about the structure of the atmosphere. If we make the approximation that the atmosphere is isothermal and exponential over a small altitude range, then there is a direct relation between the retardation and the bending angle, $R(h)=2 H(h) \epsilon(h)$ [Eq. (3)], where the scale height $H(h)$ is now allowed to vary with altitude. Since the scale height is a function of the temperature, a good approximation for $H(h)$ is to use the temperature-versus-pressure profile and the equations of state and hydrostatic pressure to find a polynomial approximation for $H(h)$. Since $\epsilon$ is a function of $h$ and we know the total doppler shift,

$$
A=\int_{t_{0}}^{t} \dot{\delta} d d t+A_{o}
$$

where $t=$ time of measurement and $t_{0}=$ time of calibration.

Equation (1) can be used to obtain a polynomial which can be solved for $h$. Combining the data from the five slave satellites gives an initial density-versus-height profile which can be used to correct temperature and scale-height curves. Using an iterative method should allow the height of the measurement to be determined accurately.

Once $h$ is known, the deviation of the true ray path from the ideal ray path, which assumes that all bending occurs at a point, can be found using ray-tracing techniques.

\section{2 Operational Considerations}

\section{2.1 Orbits}

The occultation satellites will be placed in orbit to obtain an eastwest grid spacing of $700 \mathrm{~km}$ at $40^{\circ}$ latitude and total grid-point coverage every $12 \mathrm{hr}$. North-south grid points will consist of integrated data over a 
time of $30 \mathrm{sec}$ or about $200 \mathrm{~km}$ of the earth's surface. Grid spacing is shown in Figure 4. D. 4.

Because the radio wave is bent at varying degrees as it passes through different altitudes in the atmosphere, the spacing must be as shown in Figure 4. D. 5 in order to obtain uniform height increments. Figure 4.D. 5 also shows a plot of the measurement of altitude versus latitude for each of the slave satellites, assuming an exponential atmosphere.

Station-keeping aboard all satellites will keep in-track position to within $2 \mathrm{~km}$ of nominal. Initial circularization, analysis of various components of relative velocity, and doppler ground tracking should enable the height of the satellites to be determined to within $\pm 30 \mathrm{~m}$.

In order to obtain maximum coverage, three systems will be launched into polar orbit. The orbit will be circular at a height of $920 \mathrm{~km}$ giving slightly less than 14 revolutions per $24 \mathrm{hr}$. This orbital period will allow the satellite ground track to shift gradually so that ice sounding and other high-resolution measurements can be made. An orbit in this height range minimizes perturbations from drag and from magnetic, solar, and lunar effects. At 920 $\mathrm{km}$, satellites can be seen on every pass by Fairbanks, Alaska, which can be used as a data-collection center.

Three systems will be launched at a time using the Thor-Agena booster or its equivalent. The launch must be polar to within $1^{\circ}$ and have the correct altitude to within 50 nautical miles, with the initial eccentricity less than 0.05. Positioning jets will then move two of the packages $120^{\circ}$ in opposite directions so that three packages are in the same orbit and approximately $120^{\circ}$ apart. The packages will then be circularized until eccentricity is less than $5 \times 10^{-5}$, determined by ground-tracking techniques. Circularization will require a coarse adjustment and then fine control using small pulses. At this point, the slave satellites will be ejected simultaneously and positioned accurately using the doppler-shift equipment aboard the master satellite. The positioning of slave satellites will be done using small enough $\Delta V^{i}$ s so that slight errors will not affect their common eccentricity. Positioning will require about 4 days. The master satellite will then move forward $7300 \mathrm{~km}$ to its operational position. Fine recircularization will be necessary to obtain again eccentricity less than $5 \times 10^{-5}$; however, this time the reference will be the relative-velocity component of the slave satellites due to eccentricity. This circularization process will allow subsequent station-keeping to be concerned only with correcting drift error. Table 4. D. 3 gives the necessary velocity increments needed for each maneuver. 


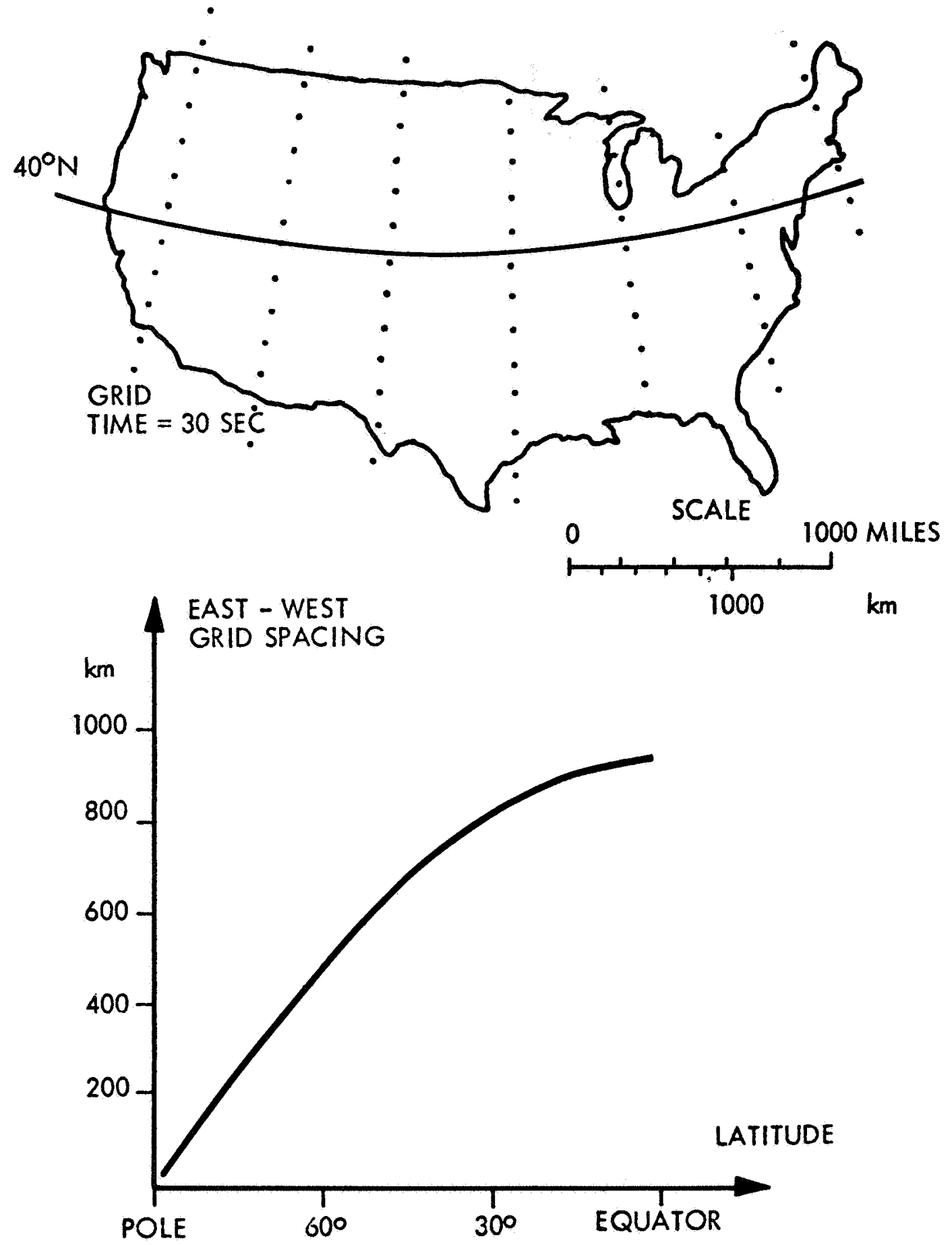

FIGURE 4. D. 4 Grid spacing with occultation satellites. 


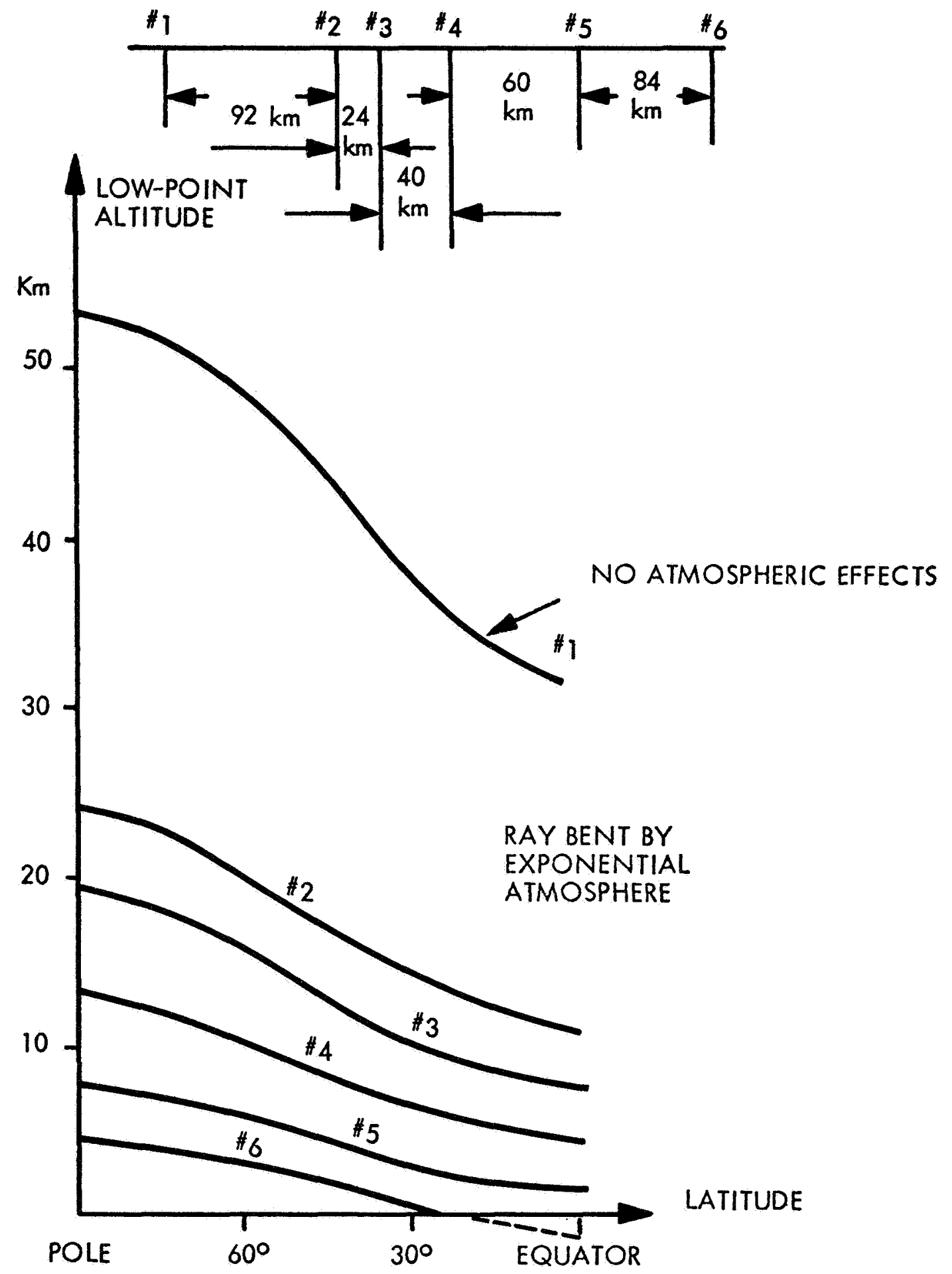

FIGURE 4.D. 5 In-track spacing of slave satellites. 
TABLE 4. D. 3

INCREMENTAL VELOCITY REQUIREMENTS

\begin{tabular}{|c|c|c|c|c|}
\hline Maneuver & $\begin{array}{l}\text { Total } \Delta V \\
\text { Required } \\
(\mathrm{m} / \mathrm{sec})\end{array}$ & Mode & $\begin{array}{l}\text { Estimated } \\
\text { Mass before } \\
\text { Correction } \\
\text { (kg) }\end{array}$ & $\begin{array}{l}\text { Fuel } \\
\text { Mass } \\
(\mathrm{kg})\end{array}$ \\
\hline \multicolumn{5}{|l|}{ Master Satellite } \\
\hline $\begin{array}{l}\text { Initially space } \\
\text { packages in } 4 \\
\text { days }\end{array}$ & 16 & $\begin{array}{l}\mathrm{H}_{2} \mathrm{O}_{2} \\
\mathrm{I}=100 \mathrm{sec}\end{array}$ & 223.3 & 3.5 \\
\hline $\begin{array}{l}\text { Coarse cir- } \\
\text { cularization }\end{array}$ & 37 & $\begin{array}{l}\mathrm{H}_{2} \mathrm{O}_{2} \\
\mathrm{I}=100 \mathrm{sec}\end{array}$ & 219.8 & 8.1 \\
\hline $\begin{array}{l}\text { Fine cir- } \\
\text { cularization }\end{array}$ & 2 & $\begin{array}{l}\mathrm{H}_{2} \mathrm{O}_{2} \mathrm{I}=200 \mathrm{sec} \\
10^{-2} \mathrm{~m} / \mathrm{sec} \text { pulses }\end{array}$ & 211.7 & 0.2 \\
\hline $\begin{array}{l}\text { Achieve station } \\
\text { in } 4 \text { days }\end{array}$ & 14 & $\mathrm{H}_{2} \mathrm{O}_{2}$ & 108 & 1.5 \\
\hline Recircularization & 0.5 & $\begin{array}{l}\mathrm{H}_{2} \mathrm{O}_{2} \\
10^{-2} \mathrm{~m} / \mathrm{sec} \text { pulses }\end{array}$ & 106.5 & 0.3 \\
\hline \multirow[t]{2}{*}{$\begin{array}{l}\text { Station-keeping } \\
\text { (3 years) }\end{array}$} & 3 & $\begin{array}{l}\mathrm{H}_{2} \mathrm{O}_{2} \\
10^{-3} \mathrm{~m} / \mathrm{sec} \text { pulses }\end{array}$ & 106.2 & 0.2 \\
\hline & & & TOTAL & 13.8 \\
\hline \multicolumn{5}{|l|}{ Slave Satellites } \\
\hline $\begin{array}{l}\text { Achieve station in } \\
4 \text { days }\end{array}$ & 0.3 & $\begin{array}{l}\mathrm{H}_{2} \mathrm{O}_{2} \\
10^{-2} \mathrm{~m} / \mathrm{sec} \text { pulses }\end{array}$ & & \\
\hline $\begin{array}{l}\text { Station-changing } \\
\text { capability }\end{array}$ & $\begin{array}{l}\text { Same as } \\
\text { above }\end{array}$ & & & \\
\hline Station-keeping & 1 & $\begin{array}{l}\mathrm{H}_{2} \mathrm{O}_{2} \\
10^{-3} \mathrm{~m} / \mathrm{sec} \text { pulses }\end{array}$ & & $\begin{array}{l}\text { TOTAL } \\
\text { FUEL } \\
\text { MASS: } \\
100 \mathrm{~g}\end{array}$ \\
\hline
\end{tabular}


All eccentricities will be maintained below 0.00005 , which is equivalent to a difference of $400 \mathrm{~m}$ between apogee and perigee. A satellite in such a slightly elliptical orbit will appear to travel in a small ellipse if it is observed from another satellite in a perfectly circular orbit of the same height. This motion will be measured by its effect on relative velocity at a characteristic frequency and will then be incorporated into the data-height determination. Because the repeater satellites will be placed in orbit together, the eccentricities they will have should be nearly equal, so that relative spacing between repeater satellites will remain constant except for a small drift introduced by positioning maneuvers.

Station-keeping maneuvers will be accomplished by ground command after data processing has revealed drift rate and total drift for each slave. If either of these quantities is out of limits, the correction cycle will be initiated. The primary cause of drift, once initial positioning errors are corrected, will be the differential effect of the drag force on the two different satellite configurations. This effect will cause the master satellite to be slowed more quickly than the slave satellites due to its greater "presented area"-to-mass ratio. By applying velocity corrections of $4.1 \times 10^{-3} \mathrm{~m} / \mathrm{sec}$ every 2 days to the transmitter satellite, it can be kept within $\pm 1 \mathrm{~km}$ of its nominal position relative to the slave satellites. Other perturbations that cause drift should be small enough so that the drift limits can be met with corrections on the order of $5 \times 10^{-3} \mathrm{~m} / \mathrm{sec}$ every 2 days. Station-keeping thrusts will be applied in a tangential direction every 26.5 orbits and should not affect eccentricity appreciably. 



\section{APPENDIX E}

\section{ATMOSPHERIC-TEMPERATURE-AND-HUMIDITY-PRO FILE MEASUREMENT BY INVERSION OF MICROWAVE RADIOMETER MEASUREMENTS MADE NEAR THE $\mathrm{O}_{2}$ AND $\mathrm{H}_{2} \mathrm{O}$ EMISSION LINES}

\section{E. 1 Statement of Measurement Problem}

To measure the atmospheric temperature and moisture profiles from satellites.

\section{E. 2 Recommended Approach}

E. 2. 1 Theory of the Technique

The temperature profile is obtained by inversion of the radiativetransfer equations. Balloon flights have been made to confirm this measurement method experimentally. Although agreement between theoretical and experimental data was poor in the tropopause, it was concluded that the measurement method was sound and that good agreement could be obtained after the shape of the $\mathrm{O}_{2}$ emission spectrum in the microwave region was better known.

The humidity is to be obtained by a similar inversion technique using measurements on the 22- $\mathrm{GHz} \mathrm{H}_{2} \mathrm{O}$ line.

E. 2.2 Alternate Possibilities.

Infrared temperature-sounding methods can be used instead.

\section{E. 3 Research and Development Plan}

\section{E. 3.1 Usefulness of Present Research and Development}

The temperature-sounding method is unique in that it obtains the temperature profile as a direct function of pressure altitude, i. e., $T(p)$. Therefore the Apollo A Integrated Passive Microwave Experiment II, "Atmospheric Temperature from 12 to $75 \mathrm{~km}$ Utilizing Microwave Emission from Molecular $\mathrm{O}_{2}$ " is well worthwhile.

However, Experiment I, "Microwave Spectral Measurements near the $1.35 \mathrm{~cm}$ Water Vapor Resonance," also on Apollo A, does not appear to 
be so definitely warranted. Figure 4 (p. 2878) of Staelin's paper* shows that all the bell-shaped weighting curves have significantly large amplitudes at zero altitude, except for the weighting function centered at $30 \mathrm{~km}$. This means that instead of observing a radiant brightness characteristic of the water vapor alone, a large component of terrain emission contaminates the signal. As a matter of fact, the total atmospheric attenuation, vertically through the atmosphere on the $1.35-\mathrm{cm} \mathrm{H} \mathrm{H}_{2} \mathrm{O}$ line, is only about $1 \mathrm{~dB}$. For near unity surface emissivity, such as is obtained over vegetated terrain, about 75 percent of the thermal signal (even on the absorption peak) will not be $\mathrm{H}_{2} \mathrm{O}$ emission. Attempts to subtract out ground emission by measurement of this quantity at longer wavelengths do not appear feasible. This occurs because the variation of emission with wavelength, which must be known to extrapolate to the emission around $1.35 \mathrm{~cm}$, will not be a well-behaved function of frequency due to the great variability of terrain type.

These statements are confirmed by the description of an experiment in a report issued by the NASA Electronics Research Center**, which says, "Over land daily variations in surface and tropospheric temperature would be obtained, but little water vapor or cloud information."

\section{E. 3. 2 Suggested Developments beyond Present R\&D Tests toward Final}

\section{Systems}

Further experimental and theoretical work is needed to determine more accurately the spectra of $\mathrm{O}_{2}$ and $\mathrm{H}_{2} \mathrm{O}$ vapor in the microwave region. The concepts of Maryott and Birnbaum concerning rotational quenching during molecular collisions, with the resultant production of a dc dipole moment with nonresonant absorbing ability, should be considered in accounting for the enormously high wing absorption of microwave absorption lines. The success of Ben-Reuven in accounting for the absorption spectrum of $\mathrm{NH}_{3}$ at all pressures from the resonant line shape to the nonresonant (Debye) line shape (including the "wings") by use of the Liouville, rather than the Hamiltonian, representation of the eigenspectrum of the molecules should also be considered.

It would also appear that work should be done on use of the solitary 2. $5-\mathrm{mm} \mathrm{O}_{2}$ line for temperature sounding. Since this line is not close to any other lines, the change in transition probabilities occurring upon line overlap in the $5-\mathrm{mm}$ region, which is suspected by Meeks and Lilley, cannot occur. This enormously reduces the problem of getting accurate absorption profiles at all temperatures and pressures. In addition, the single line maintains its

*Staelin, D. , Measurements and Interpretation of the Microwave Spectrum of the Terrestrial Atmosphere near 1-Centimeter Wavelength, J. Geophys. Res., 71, No. 12, 2875-2881, June 15, 1966.

**Interim Report on Satellite Meteorological Instruments, Report PM-6713, Electronics Research Center, National Aeronautics and Space Administration, Cambridge, Mass., June 8, 1967. 
sharp variation of absorption with frequency at high pressures. The 5-mm lines coalesce in this pressure region, so that weighting functions can only be derived from the shoulder of this composite absorption curve. As a result, the low-altitude weighting functions are sharper for the $2.5-\mathrm{mm}$ line.

\section{E. 4 Bibliography}

Barrett, A., et al., Observations of Microwave Emission by Molecular Oxygen in the Terrestrial Atmosphere, J. Geophys. Res., 71, No. 20, 4723-4734, October 15, 1966.

Ben-Reuvan, A. , Transition from Resonant to Nonresonant Line Shape in Microwave Absorption, Phys. Rev. Letters, 14, No., 10, 349-351, March 8, 1965.

Maryott, A., and G. Birnbaum, Line Shape and Collision Effects in the Microwave Wing of Far Infrared Rotational Lines (private communication).

Meeks, M. , and A. Lilley, Microwave Spectrum of Oxygen in the Earth's Atmosphere, J. Geophys. Res., 68, 1683-1703, March 15, 1963.

Rosenblum, E., Atmospheric Absorption of 10-400 KMCPS Radiation: Summary and Bibliography to 1961, Microwave J., 91-96, March 1961. 



\section{APPENDIX F \\ MEASUREMENT OF OCEAN-SURFACE TEMPERATURE AND SUR FACE-TEMPERATURE GRADIENT}

\section{F. 1 Statement of Measurement Problem}

Measurement of the ocean-surface temperature and the temperature gradient at the ocean surface produces desirable data for a synoptic weather prediction. The ocean and the atmosphere above it form a coupled system where energy is transferred between them by radiation processes. In addition, most water vapor is injected into the atmosphere by evaporation from the sea surface. This water vapor is one of the major energy sources available to drive the weather system. This energy in the water vapor is released by the process of precipitation. The sources of water-vapor injection into the atmosphere and its removal, together with the rates of injection and removal, would appear to be important data for improving the accuracy of synoptic weather prediction.

\section{F. 2 Recommendation for Approach}

\section{F.2.1 Theory of Technique}

Analysis of the microwave radiometric emission from the sea surface shows that, in the vicinity of a $20^{\circ}$ angle of inclination, the average of the vertically polarized and horizontally polarized microwave emissivity from the sea is nearly constant over a range of rms sea slopes varying from specular to $22^{\circ}$ *** This average, which can be observed by use of a circularly polarized radiometer antenna, is plotted in Figure 4. F. I (Fried's Figure 7). It may be seen that seawater having a molecular temperature of $300^{\circ}$ will have a radiant brightness varying by only $\pm 0.30 \mathrm{~K}$ over the total range of sea roughnesses when viewed at a $20^{\circ}$ inclination.

By measuring this radiant brightness, the true temperature of the sea can be determined by taking into account the variations in the complex dielectric constant of the seawater versus temperature (see Figures 4. F. 2 and 4.F.3).

*Fried, D. L. , Temperature and Roughness Dependence of Ocean-Surface Emissivity, North American Science Center Report, February 1967.

**Vecchio, E. , Scattering from a One-Dimensional Rough Surface, Autonetics Report TM 66-445-3-1, August 22, 1966. 


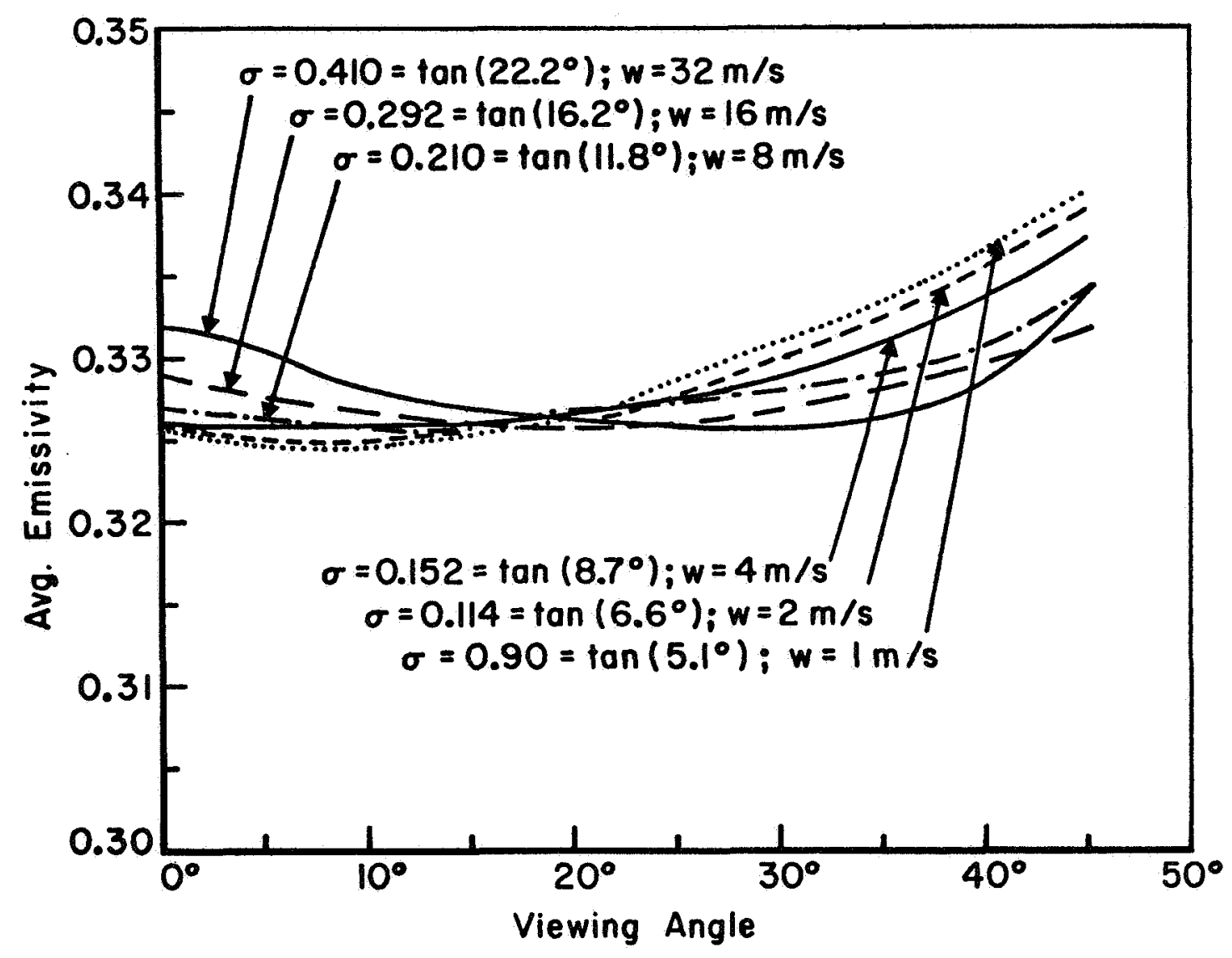

FIGURE 4.F. 1 Average emissivity versus viewing angle (two-dimensional analysis). Evaluation for: $10^{\circ} \mathrm{C}, 0.62 \mathrm{~N} \mathrm{NaCl}$ solution, $1 \mathrm{GHz}$. 


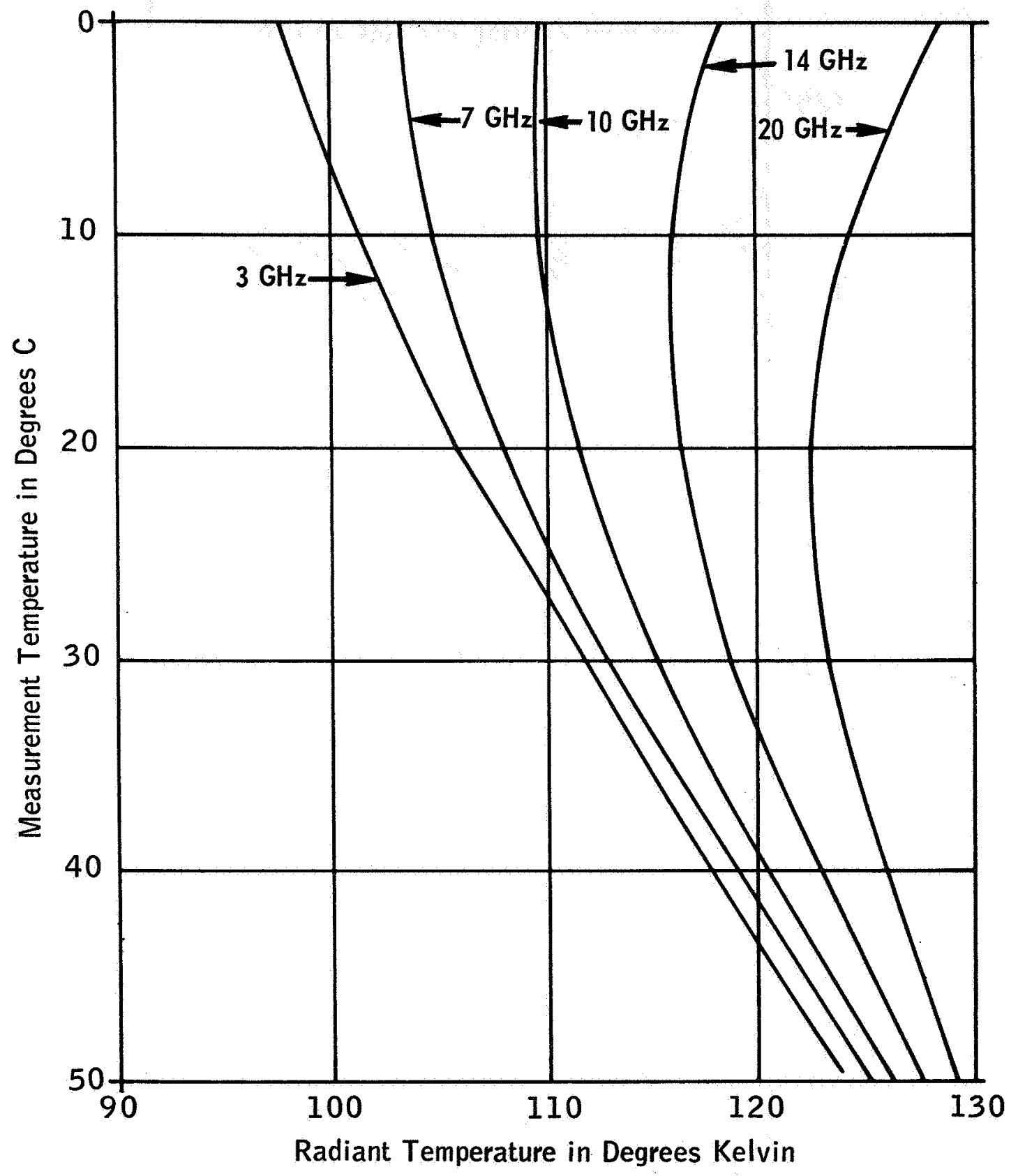

FIGURE 4.F.2 Radiant temperature for fresh water as a function of molecular temperature and frequency. 


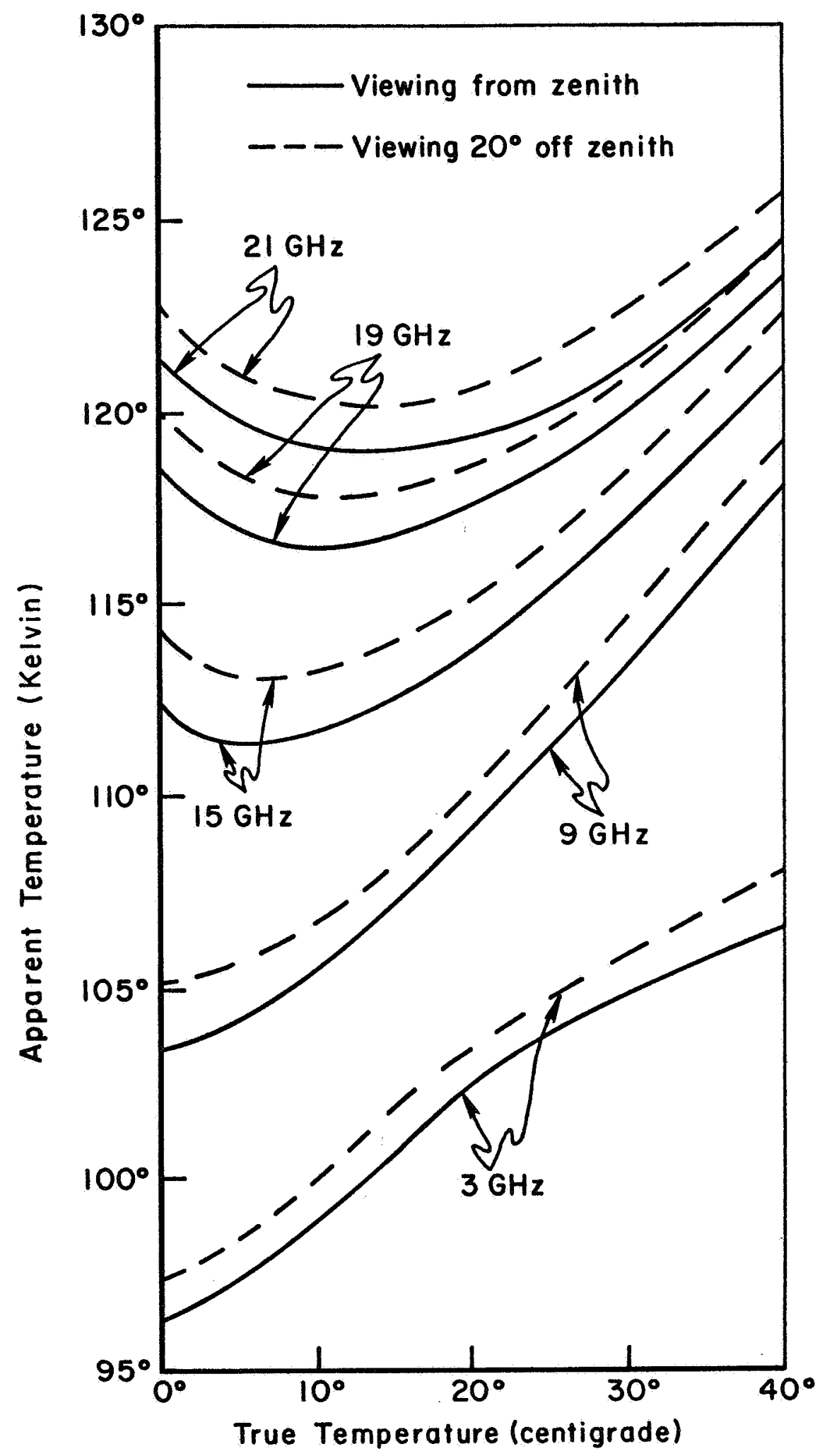

FIGURE 4.F. 3 Apparent microwave temperature versus true temperature (for $0.62 \mathrm{~N} \mathrm{NaCl}$ solution). 
Now the distance below the sea surface at which the water temperature is measured is determined by the penetration of the electromagnetic wave at the operating frequency of the radiometer. At microwave frequencies, the optical or penetration depth varies from a few tenths of a millimeter at $30 \mathrm{GHz}$ to a few millimeters at $3 \mathrm{GHz}$. At $10 \mathrm{GHz}$, for example, it is about $1 \mathrm{~mm}$.

In the first few millimeters below the surface, heat is transferred only by conduction processes, and no convection occurs. Therefore, there is a temperature gradient in this water "skin" proportional to the heat flow to the surface. This heat is dissipated at the surface by radiation to space and the atmosphere and by the production of water vapor. Because convection currents exist below a few millimeters depth, the resultant mixing stabilizes the water temperatures, so that a definite temperature gradient exists only to a depth of a few millimeters.

By measuring the true temperature of the water at two known depths within this gradient region, the heat flow to the surface can be calculated. Known depths are obtained by selection of the two operating frequencies. The lower frequency should be about $3 \mathrm{GHz}$. The upper frequency should be as high as possible in order to get as small a penetration depth as possible. This upper frequency cannot much exceed $10 \mathrm{GHz}$ because of the decreasing dependence of the apparent temperature on true temperature shown in Figure 4. F.2. These $3-\mathrm{GHz}$ and $10-\mathrm{GHz}$ radiometers should be carried on the meteorological polar orbiter.

Alternately, if the sea-surface roughness is measured by a scatterometer, the reflectivity of the sea at the inclination angle used by the radiometers $\left(20^{\circ}\right)$ can be calculated. Measurement of the scatterometer return from the sea at this inclination then makes it possible to determine the path attenuation to the sea surface. The satellite must be high enough to permit illumination of the precipitation layer over an area whose sides are large compared with the layer thickness. Otherwise the equations of radiative transfer through the scattering layer are not the same for the radiometer and the scatterometer.

F.2. 2 Alternate Possibilities

McAllister of Scripps Institute of Oceanography has experimentally demonstrated that heat flow to a water surface can be measured by an analogous method in the infrared region.

\section{F. 3 Research-and-Development Plan}

Autonetics and the Space Division of North American have built $10-\mathrm{GHz}$ and $3-\mathrm{GHz}$ radiometers for measurement of ocean-surface data. Preliminary data from these instruments can be expected in tests carried out from the end of a pier and in flight in a Scripps plane. 
The next step is the construction of a differential radiometer which measures directly the difference in radiant temperature at $10 \mathrm{GHz}$ and $3 \mathrm{GHz}$. Since the temperature difference is small, large errors can occur when temperatures at both frequencies are measured with separate instruments and then subtracted. The schematic of a radiometer for measurement of differential temperature is shown in Figure 4. F. 4.

Most errors in this radiometer will be common to both radiometer channels and subtract out, just as variations in apparent temperature due to ocean roughness and precipitation tend to subtract out.

After aircraft and pier tests of the differential radiometer system this system should be tested in one of the Nimbus and Apollo application satellites.

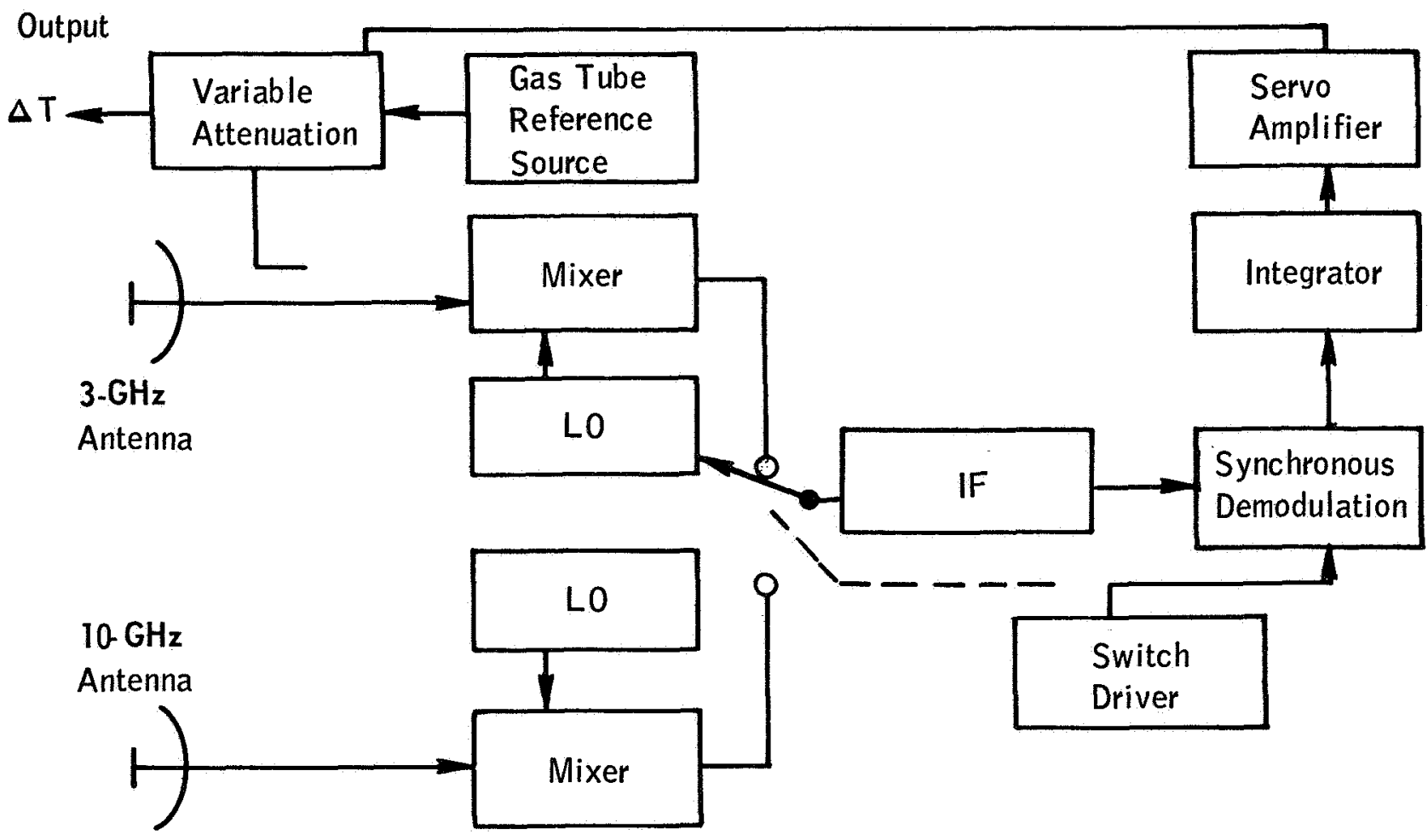

FIGURE 4.F. 4 Schematic of a differential radiometer. 


\section{APPENDIX G}

\section{RADAR FOR METEOROLOGY}

\section{G. 1 Statement of Problem}

Radar appears to have promise for measuring both precipitation and winds at the sea surface. Accuracy of precipitation measurements may be hard to establish, but certainly areas of heavy precipitation can be located. Sea-surface winds can be obtained from wave-height data, with directional information possibly obtained only from a combination of intensity with, for example, historical information and cloud patterns.

\section{G. 2 Recommendations for Approach}

\section{G. 2. I Theory of Precipitation Measurements}

Precipitation observation by radar from the ground is well established, although arguments still go on as to the degree to which rates can be established. Precipitation measurements from above are somewhat more difficult because it is necessary to distinguish between ground and presipitation echoes. Over the sea this should be much easier because the sea echo is weaker than typical ground echoes.

A radar, whose azimuth resolution is set by its antenna beam and whose range resolution is set by a range measurement, has a ratio of precipitation echo to ground echo given by $\frac{\delta_{\mathrm{v}} \mathrm{h} c}{\delta^{0}}$, where $\delta_{\mathrm{v}}$ is the scattering coefficient of precipitation in meter $2 / \operatorname{meter}^{3}, h_{c}$ is the height of the region through which the precipitation is falling, and $\delta^{\circ}$ is the differential scattering coefficient of the ground in meter ${ }^{2} /$ meter $^{2}$. Since, in the regions where Rayleigh scatter occurs, precipitation echo is proportional to the fourth power of wavelength, this ratio is higher at shorter wavelengths. With precipitation of the order of $10 \mathrm{~mm} / \mathrm{hr}$, this ratio should be at least 0.15 for a $2-\mathrm{cm}$ wavelength and a $1-\mathrm{km}$ rain thickness. At $1-\mathrm{cm}$ wavelength it is 2.4 for the same conditions. Heavier rain or thicker layers will give larger ratios. This condition is not applicable for incident angles within $10^{\circ}$ or $15^{\circ}$ of the vertical, where sea return is much stronger.

Use of a coherent radar moving-target indicator (MTI) or a combination of circular polarizations should permit enhancement of this ratio by a factor between 10 and 100, with the 100 more likely. Thus, it appears that 
it should be possible for a satellite radar to see precipitation at $2 \mathrm{~cm}$, and certainly it could do so at $1 \mathrm{~cm}$. Even over land, the MTI approach may make this possible, but more research is called for; over sea, it seems assured.

Meteorological radars for use on the ground or in aircraft normally operate at considerably longer wavelengths, because they must not only see the clouds and precipitation but also penetrate many miles through rain. A satellite system can look within, say, only $60^{\circ}$ of the vertical, so a shorter wavelength may be used because the total path through which rain attenuation may take place is relatively short.

\section{G. 2.2 Alternate Possibilities for Precipitation Measurements}

Either a synchronous satellite or one operating in a lower orbit can be used for this type of measurement. The high power associated with meteorological radars used on the ground is not necessary, partly because of the shorter wavelength and partly because the volume observed and distinguished for averaging purposes by the global system is much larger than that appropriate for tracking squall lines-with a consequent increase in signal returned for a given transmitter power.

A trial calculation for a synchronous satellite yields the astonishing result that (for conditions assumed) only about a $2-W$ average output power is needed. This is a somewhat marginal system, and a $20-W$ output would be more appropriate. On the other hand, integration was not included in the computation, so the $2-W$ system could be quite adequate with enough integration time. This will require further study of the scanning problem.

Conditions assumed are as follows:

1. Receiver noise figure: Unity (microwave radiometers already use comparable receivers that are better than this)

2. Wavelength: $2 \mathrm{~cm}$

3. Antenna dimensions: $10 \mathrm{~m} \times 10 \mathrm{~m}$

4. Precipitation: $1 \mathrm{~cm} / \mathrm{hr}, 1 \mathrm{~km}$ thick

5. Range resolutions: $75 \mathrm{~km}$

6. Azimuth resolution: $150 \mathrm{~km}$ (at 30,000-nautical-mile slant range)

7. Perfect antenna efficiency

8. Signal-to-noise ratio: 10

With a practical antenna this might be degraded so that $10 \mathrm{~W}$ would be required. Such a system, while operating, would then drain perhaps $75 \mathrm{~W}$ from the satellite power supply, although it might be designed more efficient1y. Probably it would not need to operate continuously-or, if it did, some integration would be possible, reducing the power requirement. Thus this system appears quite feasible provided the antenna can be built--and certainly this will be feasible soon. 
At the time of this writing, computations have not been made on a comparable system for a polar-orbiting satellite. However, the possibility of such a system being developed seems very good. Powers required for low-resolution radars of this type usually turn out to be negligibly small compared with the consumption of the associated equipment, although one cannot, of course, be sure until the computations are complete.

The system that would be used for this purpose would be a sidelooking real-aperture system, although use of a coherent system is called for because of the desirability of doppler processing to distinguish rain from sea.

\section{G. 2. 3 Theory for Wind Measurement}

Direct measurement of wind is indeed a difficult task. Winds at the surface of the sea may be inferred from the roughness of that surface, and techniques for making the measurement are already available and relatively unsophisticated. Some calibration will be necessary, but this seems likely to be done best from the satellite itself.

Radar return from a rough surface, such as the sea, is influenced by both roughness and composition. Since the sea, for electrical purposes of the type involved, is essentially homogeneous, measurement of the radar return can give a measure of the roughness. The roughness of the sea is determined by the present and past winds at the point of observation and at points from which waves can propagate to the point of observation. Thus, inverting the measurement of sea roughness should permit determination of the winds.

Ideally, one would like to obtain the complete directional spectrum of the waves for this inversion. Obtaining this information by radar from satellite altitude may be difficult, because it is difficult to make observations at different aspect angles and still look at the same patch of ocean. If one looks along the satellite track, the ratio of forward-looking to aft-looking observations can be established for a given point, and this can be related to the wind direction, with some ambiguity. If the ratio is unity, the track is crosswind; if it is the maximum expected for a given sea, the track is upwind or downwind (which is established by the ratio). Thus a crude measure of the wind direction may be obtained by measuring the ratio. There is also a possibility that polarization information may permit crude directional determination. A good imaging radar can actually show wavefront directions.

Details of the theoretical justification of the amplitude measurement are given in a proposal entitled Global Radar for Ocean Waves (GROW), by Moore and Pierson.

\section{G. 2. 4 Alternate Possibilities}

The simplest operational system is probably the one described in the GROW proposal. It involves a side-looking radar at the longest wavelength feasible (to obtain the larger ocean waves that fit the Pierson wave- 
analysis programs). A companion device operating at a wavelength in the 3- to $10-\mathrm{cm}$ region will undoubtedly give more information on local winds, although there is a possibility that this measurement may saturate at some as yet undetermined wind speed.

An along-track scatterometer permits determining a complete curve of scattering coefficient versus angle, from which more information on the spectrum may be obtained than with the side-looking system. The alongtrack system, however, suffers from the lack of coverage characteristic of any downward-looking-only system. Perhaps a combination of this system and the side-looking system might be desirable. This would give more information along the track and also some information from a better grid. The wave-forecasting iterative program, along with the meteorological computer programs, probably can get along better with the smaller amount of information obtainable from the side-looking system and will benefit more from the coverage it gives.

Frequency-scanned scatterometers (either side-looking or alongtrack) undoubtedly will give more information about the spectrum than the single-frequency systems. This is a topic for research, both in the sensorwave interaction and in the sensor development itself.

\section{G. 3 Research and Development Plan}

\section{G. 3. 1 Usefulness of Present Research and Development Tests}

The regrettable thing is that there are no present radar tests scheduled, except for Apollo Applications B (AAP-B)-for which no decision has been made on its existence! Clearly, the experiments scheduled for AAP-B, especially the scatterometer and altimeter-scatterometer, will provide information of value to the wind-measurement program. Processing of the synthetic-aperture data to measure precipitation may also be possible, since the relative velocity of the ground and of the drops is different with respect to the spacecraft. The scatterometer experiments proposed for this system will provide the along-track information needed to help calibrate the crosstrack GROW-type system. These experiments definitely need to be conducted.

\section{G. 3. 2 Suggested Additional Tests}

\section{G. 3. 2. I For Precipitation Measurement}

Further study of the possible systems, beyond that possible in the Summer Study, clearly is indicated. On the basis of present knowledge, however, and presuming that the additional systems calculations bear out the extremely preliminary ones to date, we can recommend several experiments.

The simplest experiment that can be performed is to process some existing synthetic-aperture data--or some that can be obtained with an existing system--to determine whether the observation of precipitation with such a system, by processing for the velocity of the drops, is indeed feasible. 
A study, and experiment if none has yet been conducted, on the feasibility of large scanning antennas for synchronous satellites is necessary. Large antennas have been planned for ATS, but the wavelength may be too long for this application.

Provided the antenna is feasible, the radar-precipitation-observation technique from synchronous orbit should be tested.

A radar system suitable for nonsynchronous-satellite observation of precipitation over the oceans should be developed and tested.

\section{G. 3. 3. 2 For Wave and Wind Observation}

As mentioned above, both along-track and GROW-type measurements should be made both at the longest possible wavelength and at a shorter wavelength that will be more responsive to the capillary and spray structure on the ocean. These systems are extremely simple and could be tested readily on small satellites.

Research into frequency-swept scatterometers should be instituted-first with aircraft flights and then with spaceflight if the expected results are obtained with aircraft. Two types of systems are contemplated:

1. A system swept over a relatively small bandwidth. The response as a function of frequency will be autocorrelated and transformed to give a measure of that part of the ocean-wave spectrum observable with the electromagnetic wavelengths used.

2. Octave-and-more-bandwidth systems should be investigated. These permit, in theory, observation of the major part of the of the ocean-wave spectrum. They will probably be useable in a GROW-type system.

Research into various schemes for determining direction of the wind-driven sea is needed. This includes along-track scatterometers, polarization effects, and imagers. Some of this research is feasible in aircraft. 



\section{APPENDIX $\mathrm{H}$}

\section{APPLICATION OF LIGHT SCATTERING AND POLARIZATION}

Scattering of light in the atmosphere and polarization of light produced by this scattering can be used to obtain the following information:

1. Turbidity of the atmosphere (the total amount of aerosol or haze particles) and the level of the maximum concentration of these particles

2. Reflecting properties of the ground (this information will allow separation of the effect of turbidity and the ground reflection on the upward radiation, and its polarization, measured from the satellite)

3. Height of the top of the uniform cloud deck as determined by the polarization of the atmosphere above the clouds

4. Inclination of the reflecting elements of the sea surface in the region of the sun's glint

This information could be obtained from the polarization parameters measured at several narrow spectral regions in the ultraviolet and visible part of the spectrum. The maximum information can be derived from the measurement of the upward radiation for several zenith angles of observation (or of the sun) in at least two perpendicular azimuthal planes. This requires sophisticated equipment such as proposed for the Apollo applications program. A simple system that would measure the total intensity (without an analyzer at a suitable orientation) will provide the information but with less accuracy and several uncertainties that have to be resolved from theoretical computations and analysis. The measurement of one additional polarized component will eliminate the approximation of the position of the plane of polarization derived from the theory for a pure molecular atmosphere, without any consideration of the aerosol effects. This latter system is suitable for measurements from a synchronous satellite. Because of its great simplicity, this system will require only small modification of the existing or proposed system. 

THE NATIONAL ACADEMY OF SCIENCES is a private, honorary organization of more than 700 scientists and engineers elected on the basis of outstanding contributions to knowledge. Established by a Congressional Act of Incorporation signed by Abraham Lincoln on March 3, 1863, and supported by private and public funds, the Academy works to further science and its use for the general welfare by bringing together the most qualified individuals to deal with scientific and technological problems of broad significance.

Under the terms of its Congressional charter the Academy is also called upon to act as an official-yet independent-adviser to the Federal Government in any matter of science and technology. This provision accounts for the close ties that have always existed between the Academy and the Government, although the Academy is not a governmental agency and its activities are not limited to those on behalf of the Government.

THE NATIONAL ACADEMY OF ENGINEERING was established on December 5, 1964. On that date the Council of the National Academy of Sciences, under the authority of its Act of Incorporation, adopted Articles of Organization bringing the National Academy of Engineering into being, independent and antonomous in its organization and the election of its members, and closely coordinated with the National Academy of Sciences in its advisory activities. The two Academies join in the furtherance of science and engineering and share the responsibility of advising the Federal Government, upon request, on any subject of science or technology.

THE NATIONAL RESEARCH COUNCIL was organized as an agency of the National Academy of Sciences in 1916, at the request of President Wilson, to enable the broad community of U.S. scientists and engineers to associate their efforts with the limited membership of the Academy in service to science and the nation. Its members, who receive their appointments from the President of the National Academy of Sciences, are drawn from academic, industrial, and government organizations throughout the country. The National Research Council serves both Academies in the discharge of their responsibilities.

Supported by private and public contributions, grants, and contracts, and voluntary contributions of time and effort by several thousand of the nation's leading scientists and engineers, the Academies and their Research Council thus work to serve the national interest, to foster the sound development of science and engineering, and to promote their effective application for the benefit of society.

THE DIVISION OF ENGINEERING is one of the eight major Divisions into which the National Research Council is organized for the conduct of its work. Its membership includes representatives of the nation's leading technical societies as well as a number of members-at-large. Its Chairman is appointed by the Council of the Academy of Sciences upon nomination by the Council of the Academy of Engineering. 